\title{
Cruise ships power plant optimisation and comparative analysis
}

\author{
Victor Bolbot ${ }^{\mathrm{a}^{*}}$, Nikoletta L. Trivyza ${ }^{\mathrm{b}^{*}}$, Gerasimos Theotokatos ${ }^{\mathrm{a}}$, Evangelos Boulougouris ${ }^{\mathrm{a}}$ \\ Athanasios Rentizelas ${ }^{b}$, Dracos Vassalos ${ }^{a}$ \\ ${ }^{\text {a }}$ Maritime Safety Research Centre, Department of Naval Architecture, Ocean \& Marine Engineering, \\ University of Strathclyde, Glasgow, United Kingdom \\ ${ }^{\mathrm{b}}$ Department of Design Manufacture and Engineering Management, University of Strathclyde, Glasgow, \\ United Kingdom
}

\begin{abstract}
The stringent regulatory framework for the emissions and safety from shipping operations as well as the market pressure to reduce the operational costs has led the cruise ship industry to pursue and investigate alternative solutions for both the new-built and the existing ships by using multi-objective optimisation methods. This study aims at investigating and comparatively analysing the optimal power plant solutions for different fuel types for an existing cruise ship by employing cost, emissions and safety objectives in a lifecycle basis. For this purpose, a bi-objective optimisation method is employed to identify optimal power plant configurations of a modern cruise ship considering the actual ship operational profile and several energy system design parameters. In subsequence, availability and the blackout event frequency were estimated using availability formulas and the Combinatorial Approach for Safety Assessment. The results demonstrate that the cruise ship power plant optimal configurations with dual fuel engines operating with natural gas exhibit lower lifecycle cost and lifetime emissions, whilst demonstrating a level of the systems safety comparable to the baseline power plant configuration. Furthermore, it is concluded that an increase in the generator sets redundancy does not necessary result in a considerable improvement of the power plant safety performance.
\end{abstract}

Keywords: Cruise ship power plants, design optimisation, alternative fuels, lifetime performance comparative analysis, economic-environmental-safety metrics

\section{Highlights}

- Optimisation of cruise ship power plant for selected fuels and fuels combinations

- Comparative analysis based on lifetime economic, environmental and safety metrics

- Operating profile affects the optimal number and nominal size of generator sets

- Optimal future power plant designs will combine various technologies

- Designs with Dual Fuel engines have been suggested for the selected case study

* The two authors have equally contributed to the present research study 


\section{Introduction}

\subsection{Background}

The cruise ship industry is a highly competitive market that has been rapidly developing with both the vessels size and number constantly increasing [1]. The cruise ship industry is one of the fastest rising segments of the tourism sector [2] and one of the most carbon intensive [3]. At the same time, the stricter environmental regulations targeting at the carbon dioxide $\left(\mathrm{CO}_{2}\right)$, the sulphur oxides (SOx) and nitrogen oxides (NOx) emissions reduction have come to effect for the new-built and existing cruise ships. In this respect, optimisation of the cruise ship power plants is a measure to achieve environmentally friendly, cost-efficient and safe solutions, thus contributing towards the cruise ship operating companies viability [4].

Along with the pressure to reduce the emissions and lifecycle cost, it is necessary to ensure the safety of these systems. This can be done by considering their inherent complexity including the interactions between the various subsystems and components as well as the heterogeneity and the various control levels of the complete system [5]. As cruise ships carry a large number of passengers and crew, ensuring the safety of the power plant is paramount. Potential system malfunctions such as blackout may lead to collision, contact or grounding, which, in turn, may end up in significant human losses as well as severe environmental pollution $[6,7]$, whilst severely damaging the financial and social profile of the cruise ship operator. The recent total black out incident on-board a cruise ship [8], where all the generator sets in both engine rooms shut down due to a low lubrication oil alarm, provides a representative example of the potential safety, financial and social implications associated with black out events. In this respect, it is important to minimise the blackout probability of the cruise ships power plant designs as well as to ascertain that adequate power will be available when required [9].

Although, the vast majority of the cruise ships power plants operates by using Heavy Fuel Oil (HFO), designs operating on alternative fuels were adopted the last decade, due to the environmental regulatory framework, the increase of the fuel prices as well as the pressure exerted by the society to the cruise ship operators for more sustainable operations. A conventional solution to comply with the SOx emissions regulations (effective from 2021) is the switching to a low sulphur content fuel, as the Marine Diesel Oil (MDO), Marine Gas Oil (MGO) and Low Sulphur Heavy Fuel Oil (LSHFO) or the use of exhaust gas scrubbers. This however only reduces the SOx emissions, whilst it is expected to increase the ship operational expenditure, as the cost of the low sulphur content fuels is much higher than the HFO cost [10], whereas the scrubber installation and operating costs are also considerable [11]. Lower environmental footprint designs employing dual fuel generator sets operating with natural gas [12] (stored in a liquefied form) or methanol [13] have also been introduced. As it is forecasted in [14], the 
natural gas (NG) penetration is expected to increase rendering it the second dominating fuel in the maritime/shipping industry by 2030, whereas an equal share of the NG and marine diesel fuels is foreseen by 2040. In addition, methanol is a fuel that can be predominantly produced from fossil fuels or biomass with an almost negligible sulphur content and a carbon content half of the natural gas one. Although its heating value is much lower than the natural gas one, its low environmental footprint renders methanol as a potential marine fuel as discussed in [15]. However, as additional hazards need to be addressed in both the cases of natural gas and methanol, a challenge arises in identifying the cruise ship optimal power plant to improve the environmental and economic performance without compromising the required safety level.

\subsection{Literature review}

A number of previous studies focused on the energy efficiency optimisation and the comparison of cruise ships and passenger ships power plants. The bi-objective optimisation with objectives the life cycle cost and lifetime carbon emissions for a cruise ship energy systems synthesis was reported in [16]. It was highlighted in [16], that the carbon pricing influences the optimal cruise ships power plant configurations and their life cycle cost concluding that the traditional power plant system would be economically prohibitive in case a carbon tax is introduced. The optimal design of a hybrid electric propulsion system with diesel generator and batteries considering as objectives the fuel consumption and the carbon emissions was presented in [17] demonstrating that considering both objectives leads to better results compared to the single objective optimisation. The economic optimisation of a combined gas turbine electric and steam configuration for a cruise ship was investigated in Dimopoulos et al. [18] and the optimal power plant configuration was identified for different fuel prices. Baldi et al. [19] studied the design and operation optimisation of a cruise ship power plant configuration consisting of diesel-generator sets, a waste heat recovery system and an electric energy storage system. The results indicated that the use of a waste heat recovery systems can offer almost $5 \%$ savings, whereas the use of batteries only $1.6 \%$. Wik [20] investigated two alternative power plants for a cruise ship with dual-fuel and diesel engines and concluded that the LNG fuel and the SCR aftertreatment system are the most feasible alternatives for complying with Tier III regulations. The performance of a hybrid power plant system consisting of fuel cells and batteries was simulated for a passenger ship in [21], demonstrating an improvement on the ship energy efficiency. The fuel consumption and weight optimisation of different power plants for a cruise ship was presented in [22] identifying that gas turbines lead to environmental, weight and volume benefits. The load allocation of a hybrid cruise ship configuration with diesel engines that provide both mechanical and electric energy was optimised, offering $3 \%$ operational cost savings in [23]. Ancona et al. [24] optimised the energy efficiency of a cruise ship by considering load allocation and proposed different strategies for 
the on-board energy management. Jeong et al. [25] reported a comparison between a diesel-electric power plant, a hybrid-electric power plant with batteries and a diesel-mechanical power plant for a ferry in terms of cost, environmental impact and safety by using expert ranking and estimating the risk priority numbers for subsystems failures. The results indicated that the hybrid propulsion system offers the highest reduction of the operating costs. The design of a cruise ship power system optimisation with objectives the system total cost and size was investigated in [26] demonstrating that the solar panel and wind turbines were not identified among the optimal solutions.

According to Solem et al. [27], the ship varying operating profile needs to be considered in the design process of a ship power plant as it affects the power plant configuration and financial-environmental performance due to the variable engines efficiency in different operating conditions. Similarly, [28] concluded that the expected ship plant operating profile needs to be employed for accurately assessing the cruise ship energy system performance in the ship design phase. The energy and exergy analyses of a cruise ship considering an actual operating profile were carried out by Baldi et al. [29], indicating the importance of the operating profile for improving the cruise ship operational energy efficiency.

A number of previous studies have focused on the reliability and availability analysis of propulsion plants similar to the one employed on cruise ships. Chang et al. [30] compared the dual-fuel dieselelectric propulsion system availability with a number of other alternative propulsion systems for a Liquefied Natural Gas carrier using Reliability Block Diagrams. Their finding was that the dual-fuel propulsion system exhibited the lowest availability. Vedachalam and Ramadass [31] compared the reliability of different Dynamic Positioning systems, and in this way, addressed also the power plant reliability. The systems were analysed using Fault Tree Analysis (FTA) and the systems overall reliability was estimated considering the reliability of their components. The results of this study demonstrated that significant reliability improvement could be achieved with increased redundancy in the investigated power system. Dubey et al. [32] compared the reliability of the planar and threedimensional military ship power network, and the results indicated that the differences in reliability were insignificant. Santoso et al. [33] also compared the reliability of various diesel-electric propulsion systems in terms of their ability to respond to the system demands, reporting small differences in the reliability of the investigated alternative topologies. In [34], the cruise ship power plant safety was assessed in terms of post damage system availability and recommendations for the engine room locations were provided. In [35], the frequency of blackout was selected as a metric representing the system safety (instead of the reliability or availability employed in previous studies) and the Combinatorial Approach for Safety Assessment (CASA) was developed for calculating the investigated cruise ship power plant frequency of blackout. 
The studies discussed in the preceding paragraphs mostly focused on the techno-economic or the energy efficiency optimisation of cruise ships and passenger ships energy systems. Alternative technologies were investigated that can improve the energy efficiency and as a consequence, the cruise ships carbon emissions; however, the $\mathrm{CO}_{2}$ emissions as an objective in the optimisation process has been employed only in a limited number of the previous studies. In addition, the previous studies focused on the comparison of cruise ships alternative power plants, the operational optimisation of an existing power plant or a predefined power plant optimisation. Furthermore, the importance of the real operating profile for the power plant selection was indicated, however the impact of optimal power plants for different operating profiles has not been assessed. Moreover, the previous studies focused on the comparison of the reliability and availability metrics for different power plants, instead of the safety related events in cruise ship power plants such as blackout.

The preceding discussion reveals the following research gaps in the pertinent literature: (a) holistic comparative analysis of the alternative cruise ship power plant designs in terms of metrics reflecting emissions, cost, availability and safety for various fuel combinations has not been reported; (b) sensitivity assessment of the optimal solutions with respect to the employed ship operational profile for cruise ships has not been presented.

This study aims at optimising an existing cruise ship power plant for different fuel types by considering the actual ship operational profile, and comparatively analysing the identified optimal cruise ship power plants in terms of a number of metrics including emissions, cost and safety at a life-cycle basis. In addition, the impact of the ship operational profile on the optimal solutions and their characteristics is assessed. Therefore, this study novelty stems from the combination of state of the art methods for estimation of financial, environmental and safety metrics, which provides new insights for the cruise ships power plants design.

The remaining of this study is organised as follows. In Section 2, a description of the employed methodology is provided. In Section 3, the required input for the implementation of the methodology is presented. In Section 4, the optimal solutions along with their estimated metrics are provided and discussed. The main findings of this study are summarised in Section 5. 


\section{Methodology}

\subsection{Methodology overview}

The methodology followed for accomplishing the aim of this study includes the following four steps as also presented in Figure 1:

1) Optimal solutions identification based on a bi-objective optimisation.

This step includes the identification of the optimal solutions for the investigated cruise ship power plant for the selected fuel type and the fuels combinations. The optimisation is carried out by using the Non-Sorting Genetic Algorithm II (NSGA-II) considering as objectives the Life Cycle Cost (LCC) and the lifetime $\mathrm{CO}_{2}$ emissions $\left(\mathrm{LTCO}_{2}\right)$ whilst taking into account the regulatory constraints.

2) Selection of the most carbon efficient solution on the Pareto front for each fuel type.

The output of the LCC and $\mathrm{LTCO}_{2}$ emissions bi-objective optimisation leads to a variety of optimal solutions. In this step, the Pareto front optimal solutions are analysed and the solution with the lowest lifetime carbon emissions for each fuel (and fuel combination) is identified.

3) For the identified optimal solutions, the lifetime non-greenhouse emissions and safety metrics including the SOx and NOx emissions, as well as the blackout frequency of occurrence and the plant generators availability are estimated.

In this step, the lifetime SOx and NOx emissions of each identified optimal solution are calculated by using the respective fuels lifecycle consumption (calculated from the previous step) along with the appropriate emissions factors. In addition, the optimal plant blackout frequency is estimated based on a method that combines the system theoretic process analysis, the events sequences identification and the fault tree analysis complemented by a quantitative analysis based on the investigated system components failure rates estimation taken from the pertinent literature.

4) Ship operating profile sensitivity analysis.

In this step, a sensitivity analysis is carried out for the selected fuels and their combinations by considering an additional operating profile with higher frequency of occurrence on higher power demand. The first two steps of this methodology are repeated to identify the optimal solutions as well as the associated lifecycle metrics.

5) Holistic comparative analysis of the different optimal solutions and results discussion. 
In this step, the identified optimal solutions lifecycle metrics are compared and discussed to conclude on these solutions advantages and disadvantages with regard to their economic, environmental and safety performance.

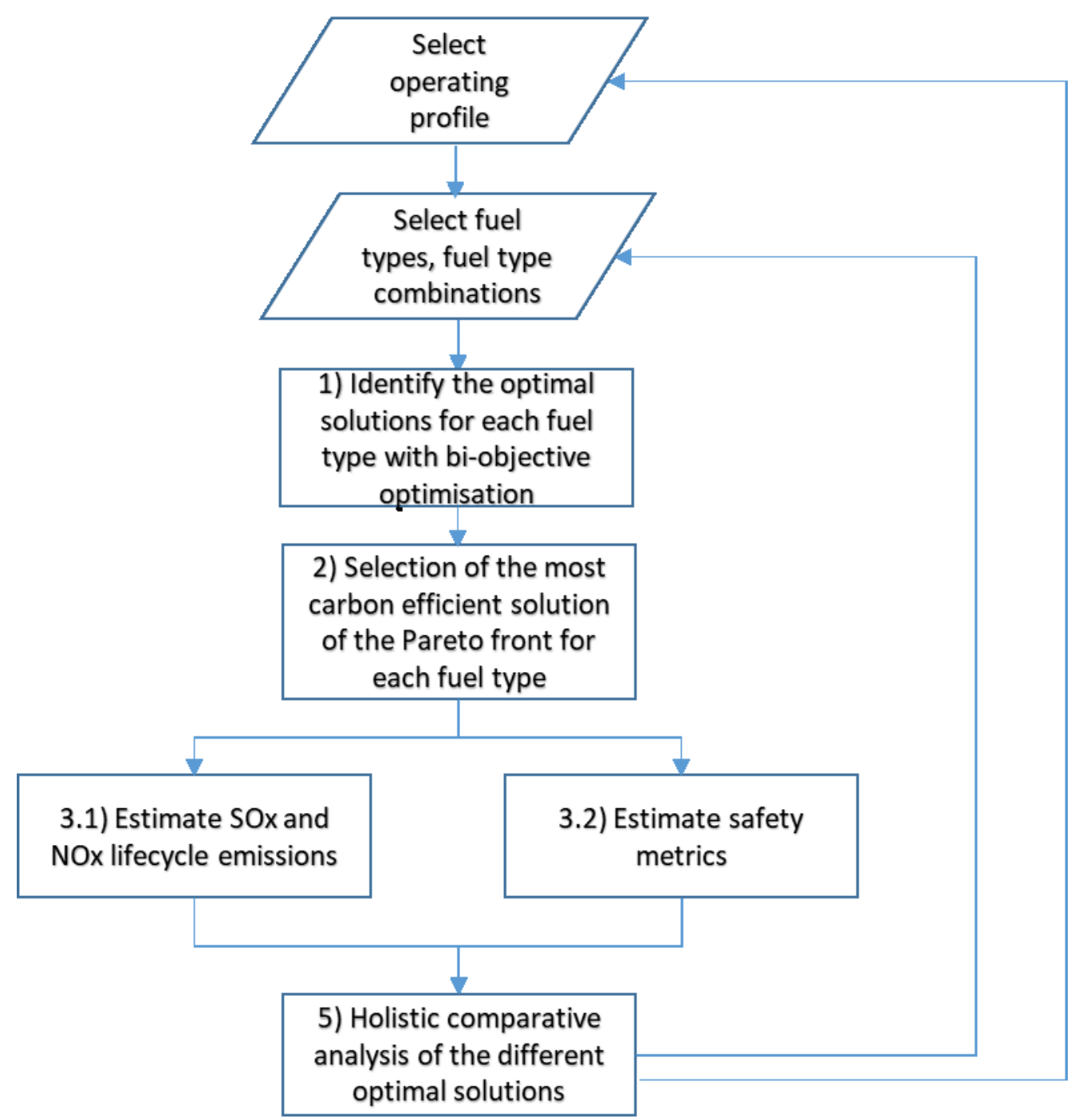

Figure 1 Followed methodology flowchart.

\subsection{Bi-objective optimal solutions identification}

In this study, the bi-objective optimisation method presented in [16], which employs the multiobjective evolutionary algorithm, NSGA-II developed by Deb et al. [36], is used to optimise the investigated cruise ship power plant for the selected fuels or fuels combinations. The flowchart of this method is presented in Figure 2.

The method requires as input a number of parameters including the ship characteristics (ship type and deadweight), as well as the expected voyage details including the time percentage the vessel sails within Emission Control Areas (ECAs) and a representative annual operating profile (in terms of frequency of occurrence against power demand). The latter is usually derived from measured or 
available operating data of similar ships and it is assumed that it represents the whole lifetime of the investigated ship. The IMO imposed limits for the NOx, SOx emissions as well as the Phase 1 Energy Efficiency Design Index (EEDI) (corresponding to the $\mathrm{CO}_{2}$ emissions limits) are taken into account for setting constrains, so that the solutions that do not comply with these limits are rejected. The IMO NOx Tier III regulations are considered, whereas the IMO regulation enforcing the usage of marine fuel with sulphur content $0.5 \%$ and $0.1 \%$ outside and inside of ECAs from 2020 is taken into consideration. Finally, the optimisation method input parameters include the investigated ship power plant cost and emissions factors, which are employed for the calculations of life cycle cost and emissions. These input parameters are derived from the pertinent literature as well as manufacturers reports as presented in Section 3.

To estimate the performance and emissions parameters of the investigated ship energy system, mathematical models were developed, which are based on the algebraic equations presented in [16]. The constants of the employed mathematical expressions for the system components main performance parameters (brake specific fuel consumption, exhaust gas flow rate, exhaust gas temperature) were derived by using regression analysis of the respective data available from the literature and manufacturers' project guides.

The decision variable values are determined by the optimisation algorithm and are provided to the employed cruise ship power plant model. The optimisation variables for each alternative power plant include the number of generator sets and their nominal power. The nominal power of the main engine is modelled as a discrete decision variable with a step of $500 \mathrm{~kW}$ within a range from 1,000 to $16,000 \mathrm{~kW}$. The total number of the selected generator sets can be from 4 to 8 whilst considering the following constraints: (a) the number of the generator sets in each engine room must be the same; (b) the total installed power in each engine room must be the same, and; (c) two engine rooms are considered for the investigated cruise ship for providing an adequate redundancy. The output parameters of the cruise ship power plant model are employed to calculate the objective functions of the multi-objective optimisation algorithm. 


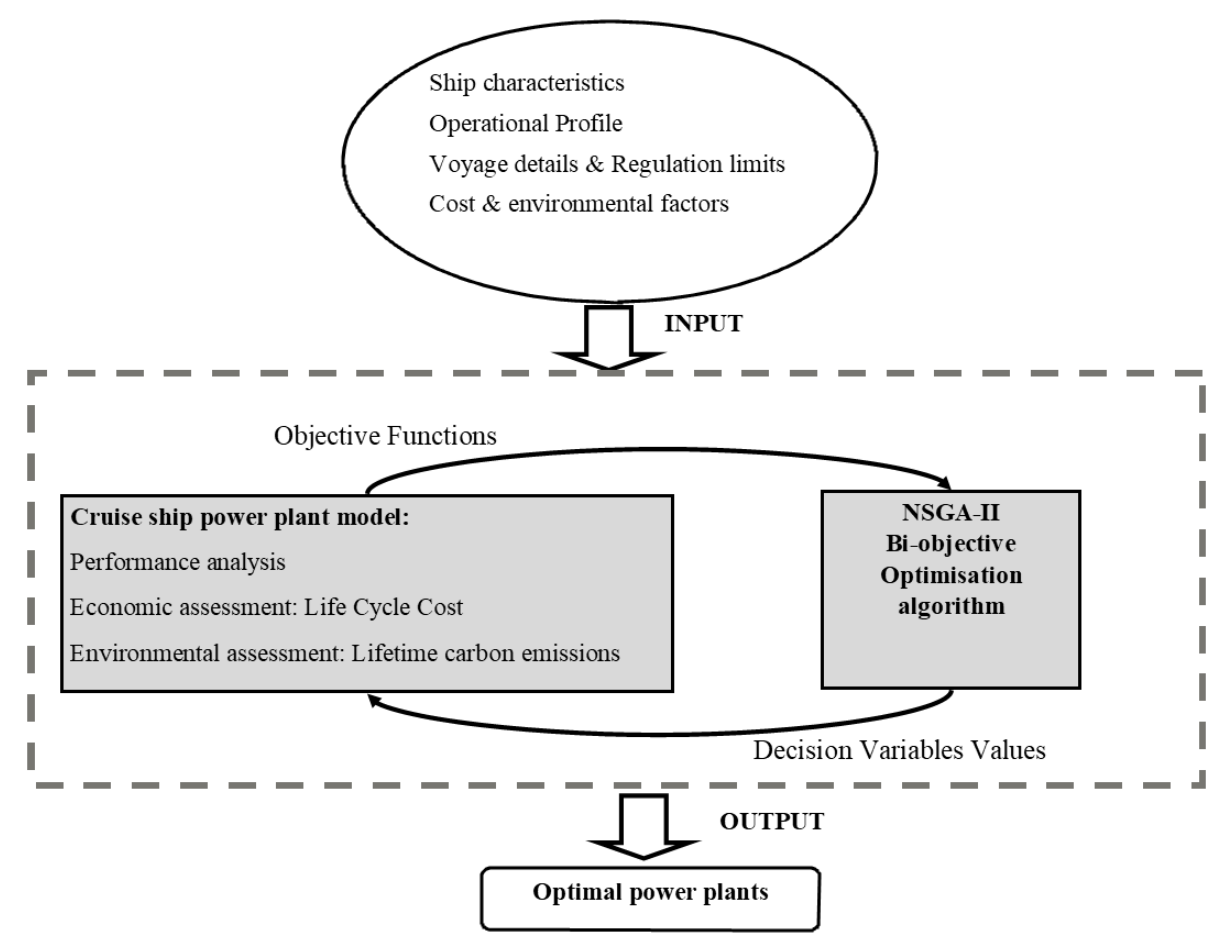

Figure 2 Optimisation method flowchart

In this study, two objectives are employed; in particular, the Life Cycle Cost (LCC) and the lifetime $\mathrm{CO}_{2}$ emissions. For identifying the Pareto optimal solutions, the NSGA-II non-dominance algorithm is used according to which, following the evaluation of the objective functions, the individual solutions are first ranked and the selection, crossover and mutation operators of the genetic algorithm are subsequently implemented. In addition, the solutions were checked against the set constraints, so that the derived plant configurations comply with the $\mathrm{IMO} \mathrm{NO}_{x}$ and $\mathrm{SO}_{\mathrm{x}}$ emissions regulations. The process is repeated until the termination criteria are met. The output of the optimisation includes the characteristics of the identified optimal power plants solutions.

The lifecycle cost (LCC) is calculated taking into account the power plant capital cost (CAPEX) and the operational expenditure (OPEX) brought to the present value according to the following equation:

$L C C=C A P E X+\sum_{n=1}^{Y} \frac{O P E X_{n}}{\left(1+d_{r}\right)^{n}}$

where $n$ denotes the $n^{\text {th }}$ year of operation, $d_{r}$ the discount rate employed to bring the OPEX in present value and; $Y$ is the last year of the system lifetime.

The capital cost is calculated according to the following equation:

CAPEX $=\sum_{s} C_{c, s} N_{s} P_{n o m, s}$ 
where $s$ denotes the $s^{\text {th }}$ power plant system/subsystem including the generator sets and the emission reduction technologies; $P_{\text {nom, }}$ denotes the $s^{\text {th }}$ system/subsystem nominal power in $\mathrm{kW} ; N$ is the number of identical systems/subsystems and $C_{c, s}$ denotes the cost factor in $€ / \mathrm{kW}$ for the $s^{\text {th }}$ system/subsystem of the power plant.

The annual operational cost for each system includes the fuel, maintenance and consumables costs and is calculated by using the following equation:

$O P E X=\sum_{k=1}^{O P H} \sum_{f t} d_{f, k} f c_{f t, k} \frac{C_{f t}}{10^{6}}+\sum_{s} C_{m, S} P_{k, s} h_{k}+M_{c o n}$

where $k$ denotes the $\mathrm{k}^{\text {th }}$ power plant operational phase; $C_{f t}$ denotes the employed fuel(s) price in $€ / \mathrm{t}$; $f c_{f t, k}$ is the amount in $\mathrm{g}$ of each employed fuel consumed in the $\mathrm{k}^{\text {th }}$ operational phase; $C_{m, s}$ the maintenance cost factor of the $\mathrm{s}^{\text {th }}$ system/subsystem in $€ / \mathrm{kWh} ; h_{k}$ denotes the operational hours of the $\mathrm{k}^{\text {th }}$ operational phase; $P_{k, S}$ denotes the power of the $\mathrm{s}^{\text {th }}$ system/subsystem in the $\mathrm{k}^{\text {th }}$ operational phase and; $O P H$ denotes the total number of the power plant operational phases; the increase on the fuel consumed to reflect the engine fouling and wearing is modelled with a deterioration factor $d_{f}$ according to $[37,38] ; M_{\text {con }}$ represents the cost of the consumables for the SCR and scrubber systems, which are modelled according to [39]. The maintenance of the engines considered in the investigation was considered in the OPEX according to equation 3 by adopting a maintenance costs factor $C_{m}$, which is expressed in $€ / \mathrm{kWh}$. Therefore, the maintenance cost of each engine depends on the power and running hours of the engine and the constant factor $C_{m}$.

The fuel consumption for each fuel and for each operational phase of each generator set is calculated by using the following equation:

$f c_{f t, k}=\sum_{s} s f c_{f t, k, s} \frac{L H V_{\text {iso }}}{L H V_{\text {actual } f t}} P_{k, s} h_{k}$

where $s f c_{f t, k, s}$ denotes the brake specific fuel consumption in $\mathrm{g} / \mathrm{kWh}$ (for each employed fuel) at ISO conditions of the $s^{\text {th }}$ system/subsystem for the $k^{\text {th }}$ operational phase. It must be noted that the brake specific fuel consumption is considered a function of the engine load and calculated based on algebraic equations, which were derived from manufacturers' operational data by employing regression analysis according to [16]. As sfc corresponds at ISO conditions, the ratio of the ISO fuel lower heating value $\left(L H V_{I S O}\right)$ to the considered fuel actual $L H V$ is used to calculate the actual fuel consumption.

The lifetime $\mathrm{CO}_{2}$ emissions $\left(\mathrm{LTCO}_{2}\right)$ from the generator sets are calculated according to the following equation:

$\mathrm{LTCO}_{2}=\sum_{n=1}^{Y} \sum_{k=1}^{O P H} \sum_{f t, k} C_{C O 2, f t} f c_{f t, k}$ 
where $C_{\mathrm{CO} 2, f t}$ denotes the $\mathrm{CO}_{2}$ emissions factor in $\mathrm{C} \mathrm{CO}_{2} / \mathrm{g}$ fuel of each employed fuel.

\subsection{Estimation of additional metrics}

\subsubsection{Estimation of NOx and SOx lifecycle emissions}

The lifetime NOx emissions are calculated for each generator set according to the following equation:

LTNOX $=\sum_{n=1}^{Y} \sum_{k=1}^{O P H} \sum_{s} E F_{N O x, f t, s} P_{k, s} h_{k}$

where $E F_{N O x, f t, s}$ denotes the NOx emissions factor for each employed fuel and the $s^{\text {th }}$ system/subsystem of the investigated power plant.

The lifetime SOx emissions are calculated for the generator sets according to the following equation based on each phase lifetime fuel consumption $\left(\mathrm{fc}_{\mathrm{ft}, \mathrm{k}}\right)$ for each fuel type and the respective emissions factor estimated based on the employed fuel Sulphur content $\left(\mathrm{EF}_{\mathrm{SOx}, \mathrm{ft}}\right)$ :

LTSOx $=\sum_{n=1}^{Y} \sum_{k=1}^{O P H} \sum_{f t} E F_{S O x, f t} f c_{f t, k}$

\subsubsection{Safety metrics estimation}

In this study, the blackout frequency is used as a metric to represent the investigated cruise ship power plant safety. The blackout frequency is estimated by employing the CASA method that is capable of addressing the safety assessment of complex systems, which are systems that consist of different subsystems and components (sensors, actuators, software and hardware) including the physical

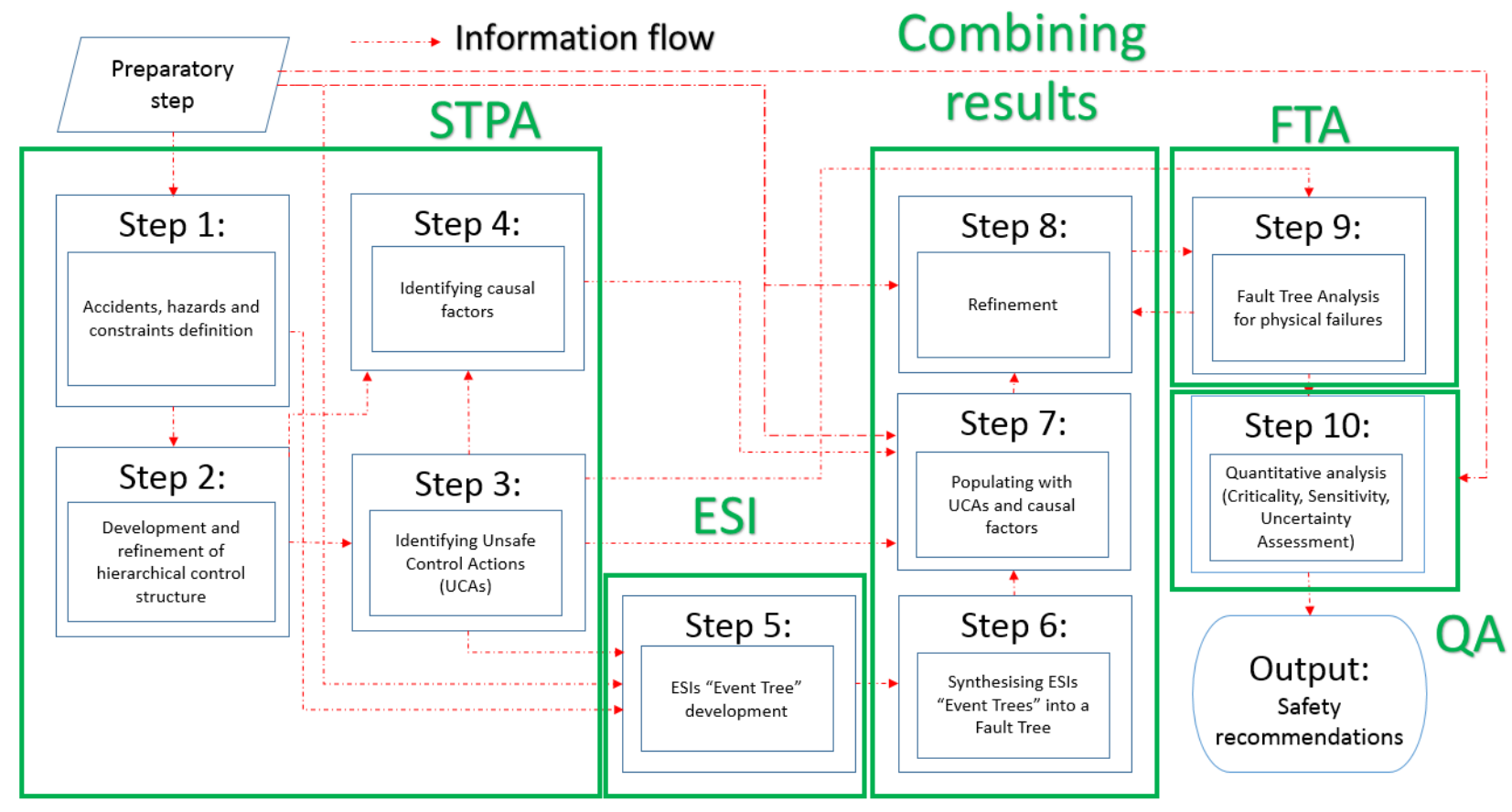

Figure 3 CASA method workflow and input-output relations. 
components, the control systems and the safety systems. The CASA method was initially introduced in [40] and described in detail in [35]; in this respect, only a short description is provided herein. The method steps and interactions are shown in the flowchart of Figure 3. The CASA method integrates the System-Theoretic Process Analysis [41] , the Events Sequence Identification [35] and the Fault Tree Analysis [42] resulting in the development of an inclusive Fault Tree that effectively captures the events/hazards combinations leading to the investigated safety event (blackout in this study). This fault tree is used in the quantitative analysis step (step 10) for accurately estimating the considered safety metric (blackout frequency). In this respect, the CASA method addresses the classical hazard identification methods deficiencies [5] by: (a) better capturing the software-intensive character of the cyber-physical systems by identifying Unsafe Control Actions (UCAs), (b) considering the potential events sequences, and (c) implementing a quantitative estimation of the safety related events.

The main assumptions employed for quantitative analysis (step 10) are the following:

- The basic events in the Fault Tree can be grouped to three categories: (a) the operating system components failures $\left(p_{i}^{o c}\right)$; (b) the safety systems failures $\left(p_{i}^{S S}\right)$ (it must be noted that the safety systems function is to control and handle the operating system components failures) and; (c) specific system states, for example overloading of the generation sets $\left(p_{i}^{S S S}\right)$.

- The considered safety systems components failure rates follow an exponential probability distribution.

- The operating system components failure rates follow either the Exponential or the Weibull probability distributions. The Weibull probability distribution is employed in the case of components for which preventative maintenance practices are followed.

- The inspection of the system components is performed according to the manufacturers' guidelines and can effectively detect the system components condition including failures and degradation level.

- The implemented maintenance practice to the systems components is according to the manufacturer guidelines and restores the system components to the best possible condition (repairing their detected faults and mitigating their degradation). The maintenance intervals of the system components are considered to be timely as proposed by the respective manufacturers.

- The blackout probability of failure in one operating mode is independent from the blackout probability of failure in other operating modes. 
The CASA method is used to calculate the frequency of the system top events. In this study, the blackout is considered to be the top event. The overall frequency of blackout (FOB in events per ship lifetime) is calculated according to the following equation by considering the frequency of blackout at each operating mode $\left(F O B_{p}\right)$ and the respective operating time fraction of each operating mode $\left(O P_{p}\right)$ :

$$
F O B=\sum_{p=1}^{q} O P_{p} F O B_{p}
$$

where $p$ denotes the system operating modes and refers to the operation with 1 generator set, 2 generator sets, etc. The $O P_{p}$ value for each operating mode is estimated by using the investigated ship operating profile.

The $F O B_{p}$ is calculated according to the following equation considering the blackout failure rate in each operating mode ( $\lambda_{\mathrm{p}}$ in events/h) along with the ship lifetime operational time (LTH in hours):

$$
F O B_{p}=\lambda_{p} L T H
$$

By definition, the failure rate is equal to the time derivative of the respective probability of failure in the considered time, provided no prior failure [43]. In this study, it was assumed that the top event probability differential can be approximated by the respective difference considering a relatively small time interval (taken as $1 \mathrm{~h}$ ). In this respect, the $\lambda_{p}$ is estimated by calculating the blackout probability at the start and end of the considered time interval of $1 \mathrm{~h}$, according to the following equation:

$$
\lambda_{p}=p_{p}\left(t_{2}\right)-p_{p}\left(t_{1}\right), \text { where } t_{2}-t_{1}=1 h
$$

For estimating the blackout probability in each operating mode $\left(P_{p}\right)$ at a specific time, the derived fault tree (from step 9) was employed. For each distinct mode of operation, the active branches of the complete fault tree are identified (whereas a number of branches are deactivated or not considered based on the components and subsystems that do not operate or do not contribute in the operation of the investigated system). In subsequence, the $P_{p}$ is calculated (for both the start and the end points of the considered time interval) from the respective fault tree taking into account the probabilities of the basic events and employing the appropriate equations describing the fault tree gates, which connect and propagate the various basic events up to the top event. Details for the fault tree analysis and the respective equations can be found in [44]. The equations used for the calculation of the basic events probabilities depending on the event or the system component type are summarised in Table 1. The required input parameters consist of the number of the redundant components, the components maintenance intervals $\left(T_{i}\right)$ and testing intervals $\left(T_{i}\right)$, the maintenance rates $\left(\mu_{i}\right)$, components failure rates $\left(\lambda_{i}\right)$, beta factor of the Weibull distribution $\left(\beta_{i}\right)$ and the probability of failure on demand for the software components $\left(P F D_{i}\right)$. 
Table 1 Equations used for the calculation of the Fault Tree basic events probability (based on [43] and [44])

\begin{tabular}{|c|c|c|c|}
\hline & System components & Equation & Eq. No \\
\hline \multirow{3}{*}{ 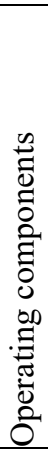 } & $\begin{array}{l}\text { Software, hardware, communication and } \\
\text { sensors failures }\end{array}$ & $p_{i}^{O C}=\lambda_{i} t$ & (11) \\
\hline & $\begin{array}{l}\text { Parts with preventive maintenance where a } \\
\text { single component failure out of } r \text { identical } \\
\text { will lead to event occurence }\end{array}$ & $\begin{aligned} p_{i}^{o C}=\sum_{1}^{r}\left(\begin{array}{l}r \\
1\end{array}\right)\left(T_{i}^{\beta_{i}-1} \lambda_{i}^{\beta_{j}}\right)^{r}(1 \\
\left.-T_{i}^{\beta_{i}-1} \lambda_{i}^{\beta_{i}}\right)^{1-r} t\end{aligned}$ & (12) \\
\hline & $\begin{array}{l}\text { Parts with preventive maintenance where } \\
\text { all the } r \text { identical components must fail for } \\
\text { event occurrence }\end{array}$ & $\begin{array}{l}p_{i}^{O C}=\left[\left(T_{i}^{\beta_{i}-1} \lambda_{i}^{\beta_{i}}\right)^{r}+r T_{i}^{\beta_{i}-1} \lambda_{i}^{\beta_{i}}\left(\frac{\lambda_{i}}{\lambda_{i}+\mu_{i}}\right)^{r-1}+\right. \\
\left.\left(\frac{\lambda_{i}}{\lambda_{i}+\mu_{i}}\right)^{r}\right] \mathrm{t}\end{array}$ & (13) \\
\hline \multirow{5}{*}{ 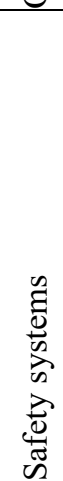 } & $\begin{array}{l}\text { Tested standby equipment that does not } \\
\text { function (except for software failures) }\end{array}$ & $p_{i}^{S S}=1+\frac{\left(e^{-\lambda_{i} T_{i}}-1\right)}{\lambda_{i} T_{i}}$ & (14) \\
\hline & $\begin{array}{l}\text { For safety system/functions with } \\
\text { continuous monitoring does not function }\end{array}$ & $p_{i}^{S S}=\frac{\lambda_{i}}{\lambda_{i}+\mu_{i}}\left(1-e^{-\left(\lambda_{i}+\mu_{i}\right) T_{i}}\right)$ & (15) \\
\hline & $\begin{array}{l}\text { Safety functions with periodical testing do } \\
\text { not function }\end{array}$ & $p_{i}^{S S}=1+\frac{\left(e^{-\lambda_{i} T_{i}}-1\right)}{\lambda_{i} T_{i}}$ & (16) \\
\hline & For software failures in safety functions & $p_{i}^{S S}=P F D_{i}$ & (17) \\
\hline & $\begin{array}{l}\text { Unavailability due to periodical } \\
\text { maintenance of standby equipment where } r \\
\text { standby components are involved }\end{array}$ & $p_{i}^{S S}=\left(\frac{1 / T_{i}}{1 / T_{i}+\mu_{i}}\right)^{r}$ & (18) \\
\hline
\end{tabular}

Another metric that is used to characterise the investigated system safety is the generator sets availability. The average availability of the generator sets that need to be connected to the operating plant is estimated as described below.

The unavailability of each one generator set is calculated according the following equation (based on [43]):

$$
U_{G}=\frac{\lambda}{\lambda+\mu}+\sum_{m}^{N_{m}} \frac{1 / T_{m}}{1 / T_{m}+\mu_{m}}
$$

where $\lambda$ denotes the generator set failure rate, $\mu$ is generator set repair rate, $T_{m}$ is the generator set inspection and maintenance interval, $\mu_{m}$ is the repair rate for the generator during the $m^{\text {th }}$ maintenance, whereas $m$ denotes the different maintenance periods. For the right-hand side of eq. (19), the first part represents the generator set unavailability due to failures during operation, whereas the second part denotes the unavailability due to implementation of preventive planned maintenance. In this equation, it is assumed that the implemented maintenance practice to the systems components is according to the manufacturer guidelines. Therefore, flexibility in maintenance intervals has not been considered, whilst in practice the maintenance can be rescheduled to avoid unavailability of the generator sets during high power demand operating periods. 
Subsequently, the unavailability of the disconnected generator sets is estimated, as it is crucial to ensure that the generator sets can be connected to the operating power plant to cover the power demand or to replace a connected generator set with a fault. The unavailability of all the disconnected generator sets in a specific configuration is calculated by using the following equation:

$$
U_{P}=\prod_{1}^{N_{G}} U_{G}
$$

The following equation is employed to calculate the unavailability of all the generator sets in the investigated system considering the operating time percentage in each operating mode $\left(O P_{p}\right)$ :

$$
U=\sum_{P=1}^{N_{P}} O P_{p} U_{P}
$$

Finally, the investigated system generator sets availability is calculated by the use of the following equation as availability is complementary to unavailability:

$$
A=1-U
$$

\subsection{Holistic comparative analysis of optimal power plant alternatives}

As a final step of the methodology followed in this study, the performance of the investigated alternative power plants for each objective as estimated according to Sections 2.2 and 2.3 is compared. First, the absolute values for each objective of the alternative solutions are discussed and the percentage difference with the baseline is identified. Then, the performance of each alternative optimal solution according to the six criteria, which are the LCC, the lifetime $\mathrm{CO}_{2}$, SOx and $\mathrm{NOx}$ emissions as well as the frequency of blackout and the system generators availability, is normalised. The normalisation is implemented by using respective metrics of the baseline solutions adapted to comply with the regulations, thus facilitating the comparison of the alternatives. The trade-offs among the alternatives are discussed and the power plant configurations that manage to reduce the LCC, the lifetime emissions without compromising the safety operation of the investigated cruise ship are proposed.

\subsection{Limitations}

The limitations of this study are as follows:

- The optimisation considers only the environmental (lifetime $\mathrm{CO}_{2}$ emissions) and economic objectives (LCC), whereas the safety objectives as well as the lifetime NOx and SOx emissions 
are assessed in a next step, as a model-based method for the automatic generation of each alternative configuration fault tree needs to be developed first. This however does not limit the novelty and accuracy of the presented results as discussed in the following section.

- Each solution capital cost is estimated as a function of the solution installed nominal power and the considered engines type; however, the same cost factor was used for different sizes of a specific engine type. This is a common practice in the literature, which however does not represent the economies of scale. In addition, the employed maintenance cost factor depends only on the engine type and the total energy (in kWh) calculated for each engine lifetime operation. Hence, the impact of the generators number and size on the maintenance cost is not considered in this study. These two assumptions are commonly employed in the pertinent literature due to the limited data availability.

- From the identified Pareto front solutions, the solution with the lowest lifetime $\mathrm{CO}_{2}$ emissions is further assessed on the safety and other environmental objectives. Additional analysis of the other Pareto front solutions is provided in Appendix A.

- Only the $\mathrm{CO}_{2}$, $\mathrm{NOx}$ and SOx emissions are considered in this study, due to the fact that they are currently regulated. Other significant gas emissions such as the methane and particulate matter can be incorporated in the methodology in future work.

- Additional operational contraints, for example operation with at least two generator sets, are not investigated herein, as they would further extend the length of this article.

- Configurations consisting of energy storage technologies including baterries [45] as well as plants alternative operating with hydrogen fuel are not considered in this study. They could be investigatd in a future work.

\section{Case studies description and analysis input}

\subsection{Case studies description}

The investigated cruise ship power plant was considered to be of the diesel-electric propulsion type, as this is the current industry standard for new designs. The power plant system generates electric power by using a number of diesel generator sets to satisfy the ship propulsion and electrical power demands. The generator sets total installed power was $72 \mathrm{MW}$. In this study, two distinct engine room spaces were considered for complying with the safe return to port regulations requirements [9].

Typically, marine heavy fuel oil (HFO) is used as the fuel of the engines of the diesel generator sets. However, in order to satisfy the strict environmental regulations (considering the existing as well as the short-term future emissions regulations), more environmentally friendly fuels that manage to reduce the $\mathrm{SOx}, \mathrm{NOx}$ and $\mathrm{CO}_{2}$ emissions, in specific, the natural gas and methanol, are considered in 
this study. The investigated power plants main characteristics are presented in Table 2, whereas the respective layouts are shown in Figure 4.

Table 2 Main characteristics of the investigated alternative solutions

\begin{tabular}{|l|l|l|l|}
\hline $\begin{array}{l}\text { Alternative } \\
\text { category }\end{array}$ & Fuel type & Generator sets type & $\begin{array}{l}\text { Emission } \\
\text { technology }\end{array}$ \\
\hline 1 & HFO or LSHFO & Diesel generator sets & $\begin{array}{l}\text { Selective Catalytic Reactor } \\
\text { (SCR) and scrubber }\end{array}$ \\
\hline 2 & Methanol \& MDO & Dual Fuel generator sets & - \\
\hline 3 & $\begin{array}{l}\text { HFO \& Natural Gas \& } \\
\text { MDO }\end{array}$ & $\begin{array}{l}\text { Combination of diesel generator sets } \\
\text { with dual fuel generator sets }\end{array}$ & - \\
\hline 4 & Natural gas \& MDO & Dual Fuel generator sets & - \\
\hline
\end{tabular}

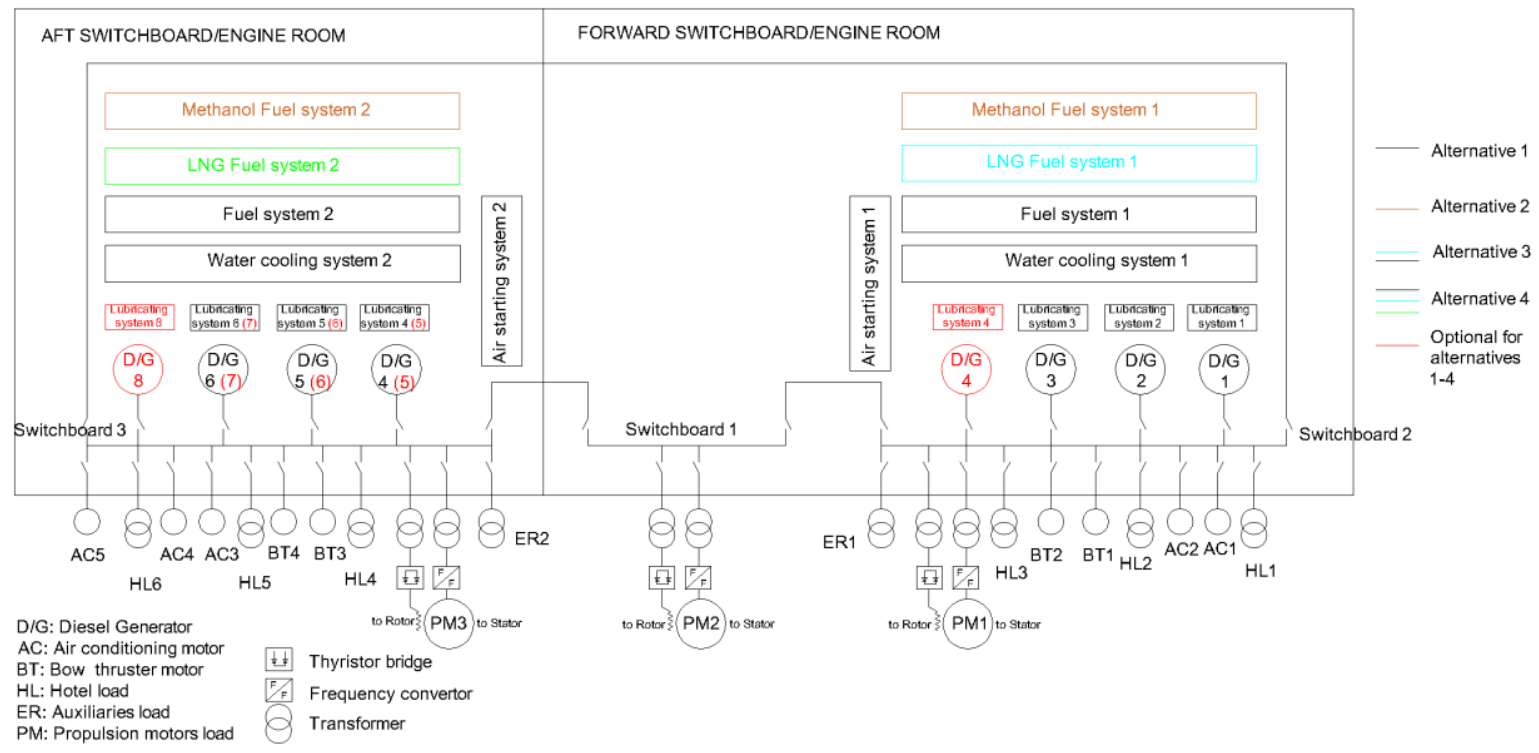

Figure 4 Investigated cruise ship power plants configurations

The following assumptions were considered for the purposes of the performed optimisation and the blackout frequency calculation:

- The investigated cruise ship operates only inside Emission Control Areas (ECAs), whereas her lifetime is 25 years.

- Only two different engine types can be installed in the ship power plant to facilitate the procurement requirements for spare parts and maintenance, which is a common industry practice.

- The engines number and nominal power are selected to satisfy the ship power requirements, whereas the engines installed in each engine room may be of a different nominal power. 
- Maximum 8 generator sets can be selected for each alternative power plant solution with a nominal power ranging from 1 to $16 \mathrm{MW}$.

- The combination of methanol and natural gas operating generator sets was not considered in this study, due to adverse effects may be incurred on the ship design complexity for accommodating both fuels storage and feeding systems.

- The generator sets start and connect to the ship electric network based on the ship electric power demand.

- The generator sets switchover is considered based on the running hours of each unit.

- The system has also the capability of changing over to another generator set in response to faults in operating generator sets.

- In cases where only one type of generator sets is considered and generator sets of different size are installed, the generator set with the lowest nominal power will be operated first.

- When more than one type of fuels are considered for the power plants, the generator sets with the most environmentally friendly fuels like natural gas and methanol will be operated first.

- The load is considered to be evenly shared in proportion to the nominal power output of the generator sets among the operating generator sets.

- Each generator set can be loaded till operating at $90 \%$ of its nominal power. Above this load level [34], an additional available generator set will start and be connected to the ship electric network for covering the power demand.

- The system includes functions for fast propulsion motors load reduction, bow thrusters electrical load reduction and preferential tripping of the air compressors of the Heating, Ventilating and Air Conditioning system (fast load reduction).

- In case of a fault in the LNG or methanol system, the system can reconfigure, so that the generator sets engines operate by using MDO or LSHFO.

As mentioned in the previous sections, the power plant operating profile was taken into account for assessing the investigated cruise ship energy systems performance. In this study, two different operating profiles were considered. The first one is shown in Figure 5(a) and was estimated based on actual operating data acquired from shipboard measurements for a period of 34 months. Using this data, the plant (and ship) distinct operational phases along with their power demand and duration (annual frequency of occurrence) were estimated. The second operating profile shown in Figure 5(b) was generated from the first one considering a 10\% higher power demand. The port operation, which corresponds to a power range lower than $12 \mathrm{MW}$, was kept the same as the original operating profile, whereas for the remaining power range (above $12 \mathrm{MW}$ ), an increase of 
the power of $10 \%$ was applied retaining the same frequency of occurrence. The $10 \%$ increase on the power requirements accounts for conditions that require additional power, for example operating with a higher ship speed, which depends on the speed management of the cruise ship, or requirement of extra power due to adverse weather conditions as well as fouled hull, etc.
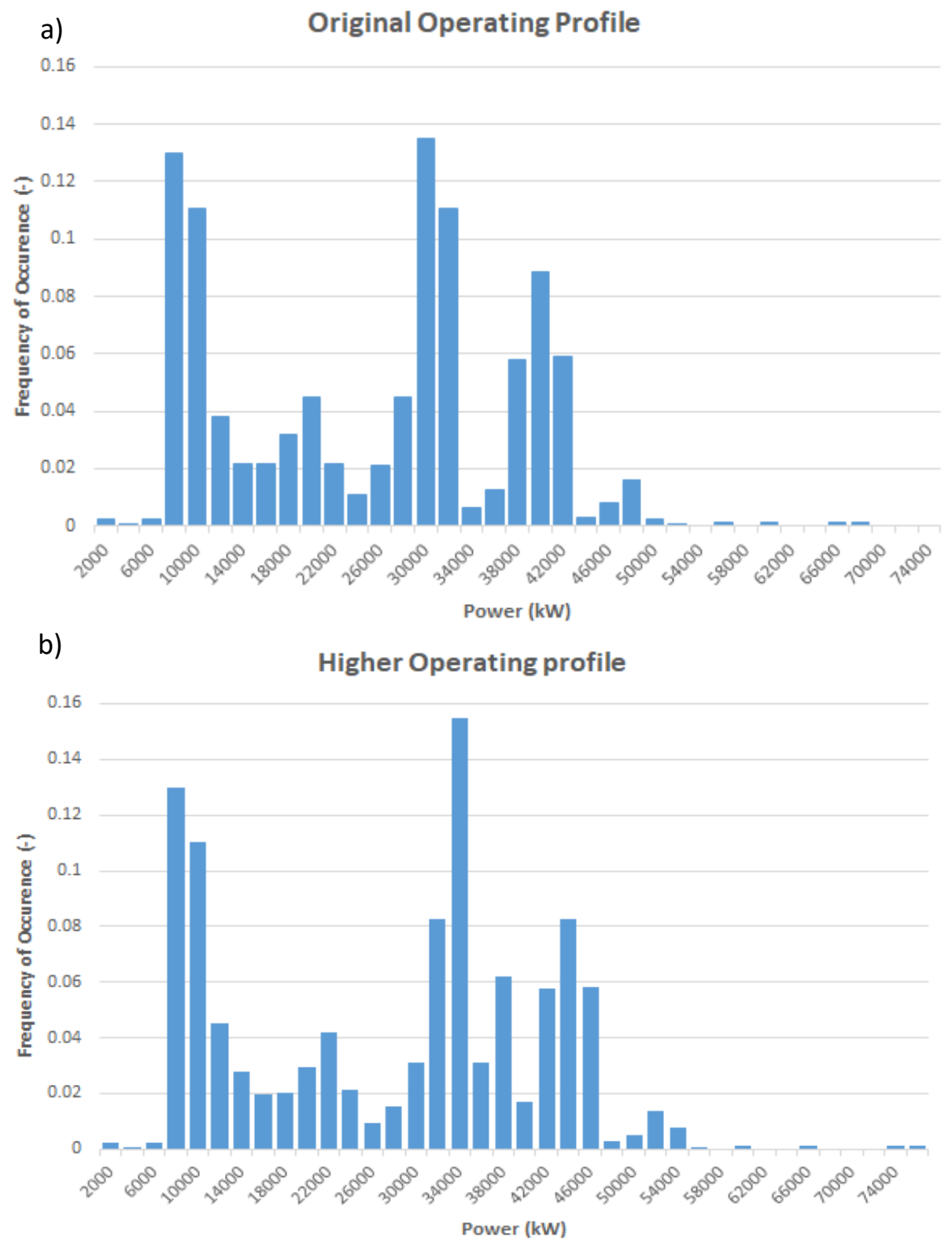

Figure 5 Considered Operational profile for the cruise ship (a) original profile; (b) operating profile with 10\% higher propulsion power demand in comparison to (a).

\subsection{Analysis input}

The considered technologies capital and maintenance costs were derived from the existing literature as well as published technical reports and are provided in Table 3. The fuels prices were derived by analysing the average fuels prices in Europe over the period 2018-2019 according to $[46,47]$. The 
fuels prices, the respective $\mathrm{CO}_{2}$ emissions conversion factors and the fuels sulphur content considered in this study are presented in Table 4.

Table 3 Capital cost of investigated technologies [16]

\begin{tabular}{|l|l|l|l|l|}
\hline Equipment type & $\begin{array}{l}\text { Capital Cost } \\
(€ / \mathrm{kW})\end{array}$ & Source & Maintenance Costs & Source \\
\hline Diesel Generator Set & 490 & {$[48]$} & $0.012(€ / \mathrm{kWh})$ & {$[49]$} \\
\hline $\begin{array}{l}\text { Dual Fuel Generator } \\
\text { Set }\end{array}$ & 740 & {$[12]$} & $0.012(€ / \mathrm{kWh})$ & {$[49]$} \\
\hline Scrubber & 70 & {$[50]$} & $\begin{array}{l}0.395 \quad\left(€ / \mathrm{kg} \quad \mathrm{SO}_{2}\right. \\
\text { removed })\end{array}$ & {$[50]$} \\
\hline SCR & 40 & {$[48]$} & $0.006(€ / \mathrm{kWh})$ & {$[51]$} \\
\hline
\end{tabular}

Table 4Fuel properties [46, 47]

\begin{tabular}{|c|c|c|c|c|c|c|}
\hline & $\begin{array}{l}\text { Price } \\
(€ / t)\end{array}$ & $\begin{array}{l}\text { Lower Heating } \\
\text { Value (kJ/kg } \\
\text { fuel) }\end{array}$ & $\begin{array}{l}\mathrm{CO}_{2} \text { conversion } \\
\text { factor }(\mathrm{kg} \mathrm{CO} / 2 / \\
\mathrm{kg} \text { fuel) }\end{array}$ & $\begin{array}{l}\text { Lower Heating Value/ } \\
\mathrm{CO}_{2} \text { conversion factor } \\
\left(\mathrm{MJ} / \mathrm{kg} \mathrm{CO}_{2}\right)\end{array}$ & $\begin{array}{l}\text { Sulphur } \\
\text { content } \\
\text { (\%) }\end{array}$ & $\begin{array}{l}\text { NOx } \\
\text { emission } \\
\text { factor }\end{array}$ \\
\hline HFO (IFO 380) & 300 & 39,000 & 3.021 & 12.910 & $2.7 \%$ & \multirow{3}{*}{$\begin{array}{l}\text { Tier II } \\
\text { compliance } \\
7.7 \mathrm{~g} / \mathrm{kWh}\end{array}$} \\
\hline LSHFO (LS380) & 350 & 41,000 & 3.075 & 13.333 & $0.1 \%$ & \\
\hline $\begin{array}{l}\text { Marine Diesel } \\
\text { Oil }\end{array}$ & 480 & 42,700 & 3.082 & 13.855 & $0.1 \%$ & \\
\hline Methanol & 400 & 20,100 & 1.375 & 14.618 & 0 & $\begin{array}{l}\text { Tier III } \\
\text { compliance } \\
1.44 \mathrm{~g} / \mathrm{kWh}\end{array}$ \\
\hline NG & 250 & 48,600 & 2.750 & 17.673 & 0 & $\begin{array}{l}\text { Tier III } \\
\text { compliance } \\
1.8 \mathrm{~g} / \mathrm{kWh}\end{array}$ \\
\hline
\end{tabular}

The required input for the CASA method implementation is provided in Table 5. The following five types of input parameters are required: (1) the system layout and functions, the number and type of the power plant components, as well as the control structure; (2) operating data for the system and components; (3) the system components failure rates; (4) the system components maintenance and inspection intervals, and (5) the system components maintenance duration. The information for the baseline system was retrieved from available system drawings and cruise ship operating data. The components maintenance, inspection duration and failure rates were taken from the available literature as described in [35].

Table 5 Required input parameters for the implementation of the CASA method.

\begin{tabular}{|c|c|c|}
\hline $\begin{array}{l}\text { Type of data used } \\
\text { for input }\end{array}$ & $\begin{array}{l}\text { Number of used } \\
\text { parameters }\end{array}$ & Example \\
\hline Design data & 50 & $\begin{array}{l}\text { Number of speed } \\
\text { sensors installed on } \\
\text { each generator set }\end{array}$ \\
\hline Operating data & 15 & $\begin{array}{l}\text { Percentage of vessel } \\
\text { operation in the sailing } \\
\text { mode }\end{array}$ \\
\hline
\end{tabular}




\begin{tabular}{|l|l|l|}
\hline $\begin{array}{l}\text { Maintenance } \\
\text { inspection } \\
\text { intervals }\end{array}$ & 29 & $\begin{array}{l}\text { Testing of circuit } \\
\text { breaker capability }\end{array}$ \\
\hline $\begin{array}{l}\text { Maintenance } \\
\text { duration }\end{array}$ & 18 & $\begin{array}{l}\text { Maintenance duration } \\
\text { of each generator set }\end{array}$ \\
\hline $\begin{array}{l}\text { Failure rates for } \\
\text { components }\end{array}$ & 175 & $\begin{array}{l}\text { Failure rate for the PMS } \\
\text { hardware }\end{array}$ \\
\hline
\end{tabular}

The failure rates for the investigated system components were primarily derived from the OREDA database [52], a number of other publications (given in Table 6) and the blackout accident investigation reports provided by an anonymous cruise ship operating company. The PDS Data Handbook [45] and the Ohio State University report [53] were used to identify the failure rates for the system software supported functions.

Table 6 List of sources for quantitative analysis.

\begin{tabular}{|c|c|}
\hline Source & Estimated parameters \\
\hline [54] & Transformer failure rates, communication lines failure rates \\
\hline [55] & Information on insulation failure rates in transformers \\
\hline$[56]$ & The current sensors failure rate \\
\hline [57] & Sea chest failure rate \\
\hline [58] & The failure rate for fuel system \\
\hline [59] & The failure rate for optical sensors \\
\hline [60] & Faults for shaft sealing system \\
\hline$[6,61]$ & Fire failure rate in the engine room \\
\hline [62] & The fuel filters failure rate \\
\hline [52] & Generator set and electrical components failure rates \\
\hline$[63]$ & Information on software failure rates \\
\hline [64] & Arc in switchboards \\
\hline [43] & Circuit breaker failures \\
\hline$[65]$ & Failure rate for marine engine pistons \\
\hline$[66-72]$ & Information on $\beta_{i}$ factors of Weibull distribution \\
\hline $\begin{array}{l}\text { Accident investigation } \\
\text { reports }\end{array}$ & $\begin{array}{l}\text { Generator set fault tripping due to oil mist detector and control malfunction } \\
=7.3810^{-6}\left[\mathrm{~h}^{-1}\right]\end{array}$ \\
\hline
\end{tabular}

\section{Results and discussion}

\subsection{Initial operating profile optimisation results}

For each selected fuel type (Table 2) and the first operating profile (Figure 5(a)), the optimisation algorithm identified the Pareto optimal solutions considering the lifecycle cost and the lifetime $\mathrm{CO}_{2}$ 
emissions. The investigated solutions, the identified Pareto fronts as well as the derived optimal solutions characteristics along with the considered safety objective values are provided and discussed in Appendix A. As it can be deduced from the derived results, the variation in safety metrics for the solutions on the Pareto front is limited, which justifies the use of the adopted methodology at this stage. All the solutions comply with the IMO Tier III NOx emissions and the SOx emissions (with effect from 2020) regulations as well as the EEDI requirements. The characteristics of the derived optimal solutions with the lowest lifetime $\mathrm{CO}_{2}$ emissions, in specific the number of generator sets and the nominal power for each engine room space, are provided in Table 7. In this table, the characteristics of the baseline power plant configuration (the existing configuration of the investigated ship) are also presented. It can be deduced from the results presented in Figure 6 that the lowest LCC is achieved by the alternative No $3 a$, whereas the lowest $\mathrm{CO}_{2}$ emissions are achieved by the alternative No 4 a.

The calculated economic, environmental and safety metrics, including the lifecycle cost, the lifetime $\mathrm{CO}_{2}$ emissions, the lifetime NOx emissions, the lifetime SOx emissions, the lifetime blackout frequency and the disconnected generator sets availability, for the optimal and the baseline configurations are presented in Figure $6(a-f)$. In these figures, the respective metrics for the baseline configuration operating with LSHFO (this is one of the options to obtain compliance with the IMO SOx emissions legislation that are coming into effect in 2020) are also presented. For each optimal solution, the percentage difference of the respective metric value from the baseline configuration value is also provided in this figure.

It should be noted that the CAPEX and OPEX of the investigated optimal configurations (presented in Figure 6(a)) greatly depend on the employed cost factors presented in Tables 3 and 4 . In addition, the LCC of the configurations is affected by the potential future carbon prices as it was reported in [16]. In this respect, a future sensitivity analysis would be beneficial for investigating the impact of the cost factors on the optimal solutions.

Table 7 Optimal configurations for each alternative power plant.

\begin{tabular}{|c|c|c|c|c|c|}
\hline Fuel type & $\begin{array}{l}\text { Type of } \\
\text { alternative } \\
\text { solutions }\end{array}$ & $\begin{array}{l}\text { Operating } \\
\text { profile } \\
\text { (Table 2) }\end{array}$ & $\begin{array}{l}1^{\text {st }} \text { Engine Type } \\
\text { Fuel } \\
\text { Emissions reduction } \\
\text { tecnologies } \\
\text { Number (-) } \\
\text { Unit Nominal Power }\end{array}$ & $\begin{array}{l}2^{\text {nd }} \text { Engine Type } \\
\text { Fuel } \\
\text { Emissions reduction } \\
\text { tecnologies } \\
\text { Number (-) } \\
\text { Unit Nominal Power }\end{array}$ & $\begin{array}{l}\text { Engine rooms } \\
\text { layout details }\end{array}$ \\
\hline $\begin{array}{l}\text { HFO or } \\
\text { LSHFO }\end{array}$ & 1 & a & $\begin{array}{l}\text { D-G sets } \\
\text { HFO } \\
\text { SCR \& Scrubber } \\
4 \\
10 \mathrm{MW}\end{array}$ & $\begin{array}{l}\text { D-G sets } \\
\text { HFO } \\
\text { SCR \& Scrubber } \\
4 \\
8 \mathrm{MW}\end{array}$ & $\begin{array}{l}\text { Engine room No } \\
1: 2 \text { units for } \\
\text { each engine } \\
\text { type } \\
\text { Engine room No } \\
2: 2 \text { units for }\end{array}$ \\
\hline
\end{tabular}




\begin{tabular}{|c|c|c|c|c|c|}
\hline & & & & & $\begin{array}{l}\text { each engine } \\
\text { type }\end{array}$ \\
\hline $\begin{array}{l}\text { Methanol \& } \\
\text { MDO }\end{array}$ & 2 & a & $\begin{array}{l}\text { DF-G sets } \\
\text { Methanol } \\
\text { Not included } \\
4 \\
11 \mathrm{MW}\end{array}$ & $\begin{array}{l}\text { DF-G sets } \\
\text { Methanol } \\
\text { Not included } \\
4 \\
7 \mathrm{MW}\end{array}$ & $\begin{array}{l}\text { Engine room No } \\
1: 2 \text { units for } \\
\text { each engine } \\
\text { type } \\
\text { Engine room No } \\
2: 2 \text { units for } \\
\text { each engine } \\
\text { type }\end{array}$ \\
\hline $\begin{array}{l}\text { HFO \& } \\
\text { Natural Gas } \\
\text { \& MDO }\end{array}$ & 3 & a & $\begin{array}{l}\text { DF-G sets } \\
\text { NG (stored in LNG } \\
\text { form) } \\
\text { Not included } \\
4 \\
12 \mathrm{MW}\end{array}$ & $\begin{array}{l}\text { D-G sets } \\
\text { LSHFO } \\
\text { SCR } \\
2 \\
12 \mathrm{MW}\end{array}$ & $\begin{array}{l}\text { Engine room No } \\
1: 2 \text { units of type } \\
1 \& 1 \text { unit of } \\
\text { type } 2 \\
\text { Engine room No } \\
2: 2 \text { units of type } \\
1 \& 1 \text { unit of } \\
\text { type } 2\end{array}$ \\
\hline $\begin{array}{l}\text { Natural gas } \\
\& \mathrm{MDO}\end{array}$ & 4 & $a$ & $\begin{array}{l}\text { DF-G sets } \\
\text { NG (stored in LNG } \\
\text { form) } \\
\text { Not included } \\
4 \\
11 \mathrm{MW}\end{array}$ & $\begin{array}{l}\text { DF-G sets: } \\
\text { NG (stored in LNG } \\
\text { form) } \\
\text { Not included } \\
4 \\
7 \mathrm{MW}\end{array}$ & $\begin{array}{l}\text { Engine room No } \\
\text { 1: } 2 \text { units for } \\
\text { each engine } \\
\text { type } \\
\text { Engine room No } \\
2: 2 \text { units for } \\
\text { each engine } \\
\text { type }\end{array}$ \\
\hline HFO & Baseline & a & $\begin{array}{l}\text { D-G sets } \\
\text { HFO } \\
\text { not included } \\
3 \\
12 \mathrm{MW}\end{array}$ & $\begin{array}{l}\text { D-G sets } \\
\text { HFO } \\
\text { not included } \\
3 \\
12 \mathrm{MW}\end{array}$ & $\begin{array}{l}\text { Engine room No } \\
1: 3 \text { units } \\
\text { Engine room No } \\
2: 3 \text { units }\end{array}$ \\
\hline
\end{tabular}

As it can be inferred from Figure 6(a), the configuration that exhibits the lowest lifecycle cost is the alternative No $3 a$, which combines 4 dual fuel generator sets operating with natural gas and 2 diesel generator sets. This alternative benefits from the low capital cost of the diesel generator sets and the low fuel cost of the natural gas. In addition, the alternative No 4a that consists of a combination of dual fuel generator sets of different nominal power (4 units of $11 \mathrm{MW}$ and 4 units of $7 \mathrm{MW}$ ) exhibits the second lowest LCC among the other solutions. Compared to the alternative No. 3a, the alternative No 4 capital cost is higher due to the higher cost of dual fuel generator sets, whereas the operating costs of these two alternatives (No $3 a$ and $4 a$ ) are comparable. This is attributed to the fact that in the case of the alternative No 3a power plant, the power demand is covered by operating only the dual fuel generator sets in most of the cruise ship lifetime. 

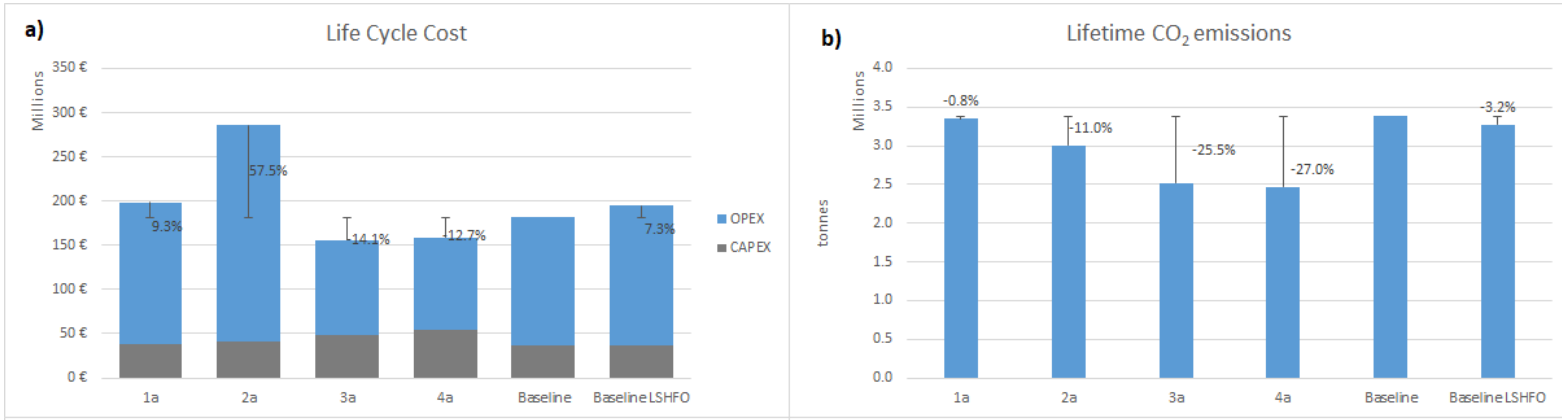

c)

Lifetime SOx emissions

d)

Lifetime NOx emissions
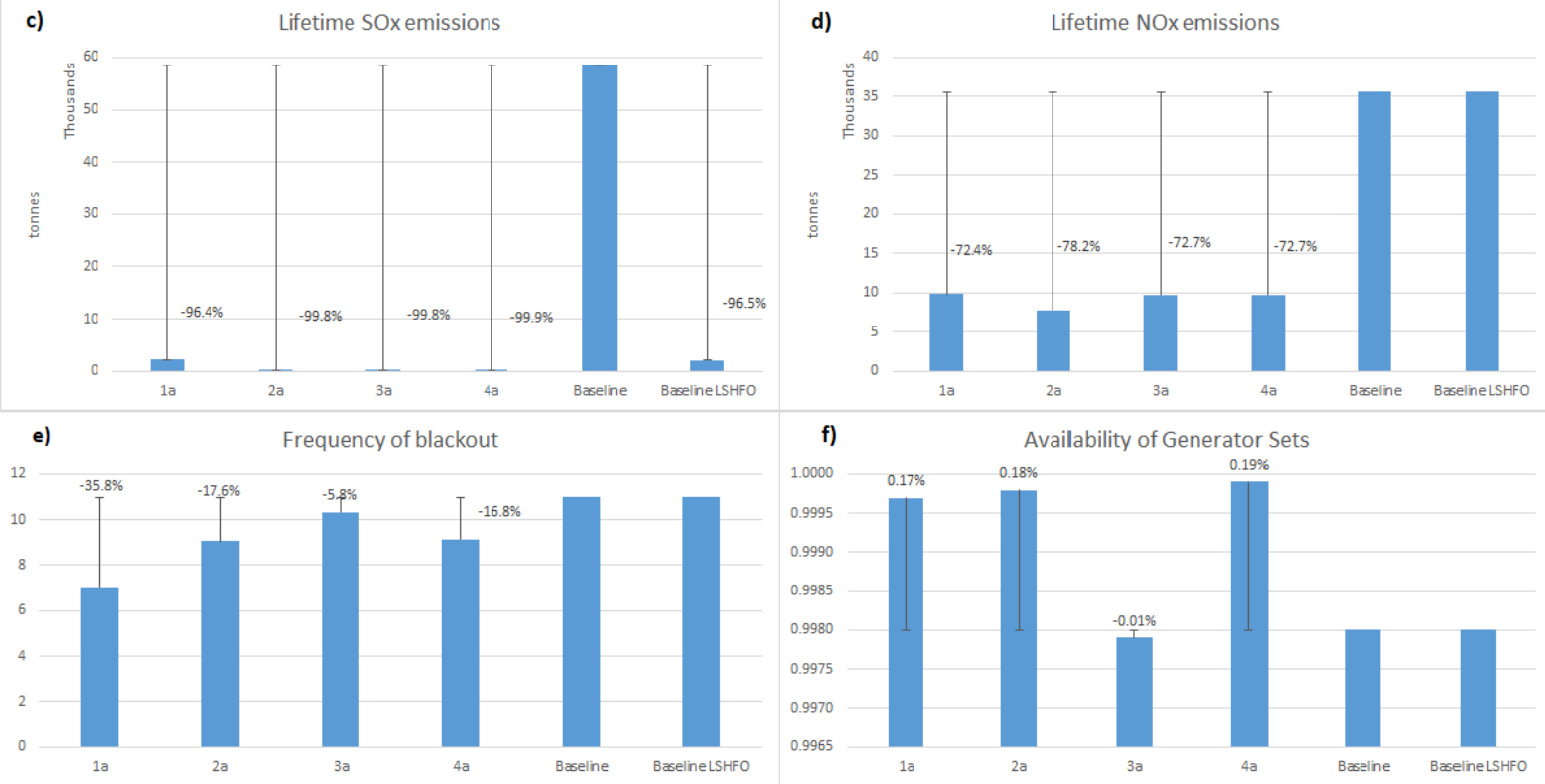

Figure 6 Lifetime economic, environmental and safety metrics of the Investigated cruise ship power plant alternative solutions derived for the first considered operating profile

The alternative No $2 \mathrm{a}$ exhibits the highest cost as it consists of dual fuel generators operating by using methanol fuel. Although, the capital expenditure for this alternative is relatively low, the operating cost is almost $60 \%$ higher than the baseline one, due to the higher price and the lower energy density of the methanol fuel. This additionally results in larger storage tanks requirements associated with a potential reduction of the cruise ship payload (passengers' number), the impact of which is out of this study scope and therefore it was not considered herein.

The LCC of the baseline power plant when operating with LSHFO is estimated to be $7 \%$ higher than the baseline LCC due to the higher price of the LSHFO; however this is subject to some uncertainty as the future prices for the LSHFO cannot be forecasted with accuracy. Finally, the alternative No. 1a exhibits a higher capital cost from the one of the baseline due to the scrubber and SCR systems installation. In addition, its operational cost is also higher than the baseline one due to the operation of the emissions reduction technologies (consumables, energy demand, and increase of the engines brake specific fuel consumption). 
With regard to the lifetime $\mathrm{CO}_{2}$ emissions (shown in Figure $6(\mathrm{~b})$ ), the alternative No 4a that consists of dual fuel generators operating with natural gas exhibits $27 \%$ lower $\mathrm{CO}_{2}$ emissions than the one of the baseline. Similarly, low $\mathrm{CO}_{2}$ emissions (reduced by $25.5 \%$ from the ones of the baseline) are observed for the alternative No 3a due to the low operating time of the diesel generator sets running on LSHFO. The alternative No $2 \mathrm{a}$ with methanol emits almost $11 \%$ less $\mathrm{CO}_{2}$ emissions than the baseline due to the methanol low carbon content. Despite the fact that methanol has lower carbon content than the natural gas, the alternative No $2 \mathrm{a}$ lifecycle $\mathrm{CO}_{2}$ emissions are higher than those of the alternative No 4a due to the methanol lower energy density (in comparison with the natural gas). Similar observations are derived comparing the results for the baseline solution; slightly lower lifetime $\mathrm{CO}_{2}$ emissions by $3.2 \%$ were estimated for the case where the baseline power plant operates with LSHFO, which is attributed to the higher LHV of the LSHFO, in spite of its slightly higher carbon content. Finally, $0.8 \%$ lower $\mathrm{CO}_{2}$ emissions were calculated for the alternative No 1 a due to the more efficient operation of the selected diesel generator sets. The selection of the diesel generator sets nominal power at two different ranges ( $8 \mathrm{MW}$ and $10 \mathrm{MW}$ ) resulted in the more efficient plant operation and the reduction of the fuel consumption at the specific operating profile. It must be noted, that the methane emissions of the investigated optimal alternative configurations, which also contribute to the greenhouse effect and reduce the benefits from the $\mathrm{CO}_{2}$ emissions reduction, were not considered in this study.

From Figure 6(c), it is inferred that the baseline power plant exhibits high SOx emissions levels (almost $59,000 \mathrm{t}$ of SOx emisions were calculated during the investigated cruise ship lifetime) in comparison with the other alternatives. The alternative No 1a (which operates with HFO and employs an exhaust gas scrubber) and the baseline when operating with LSHFO exhibit almost 96.5\% lower SOx emissions than the baselinepower plant. The alternatives No 2a and No 4a operating with methanol and natural gas, respectively, exhibit an almost complete elimination of the SOx emissions (reduction of $99.9 \%$ in comparison with the baseline case) as the sulphur content of these fuels is almost zero. The altenative No 3a operating on natural gas and LSHFO also exhibits a similar performance $(99.8 \%$ SOx emissions reduction in comparison with the baseline case) due to the fact that the diesel generator sets use LSHFO and operate for a very limited time based on the considered plant profile.

The calculated lifetime NOx emissions of the investigated power plant solutions are presented in Figure $6(d)$. The baseline solution operating with HFO and LSHFO exhibits almost the same NOx emissions that amount to approximatey $35,500 \mathrm{t}$. These solutions do not comply with the IMO Tier III NOx emissions limits. On the other hand, the alternative No 1a exhibits $72 \%$ lower NOx emissions, compared to the baseline ones due to the SCR technology. Almost 73\% lower NOx emissions are emitted by the alternatives No $3 a$ and No $4 a$ due to the usage of dual fuel generator sets operating 
with natural gas that manage to comply with the IMO Tier III NOx emissions limits (without the need for the installation of an emission reduction technology). The solution that exhibits the lowest lifetime NOx emissions is the alternative No 2a that employs dual fuel generator sets operating with methanol. The alternative No 2a exhibits almost 2,000 t of lower lifetime NOx emissions less compared with the alternative No $4 a$, as the methanol operating engines NOx emissions are lower than the ones of the engines operating with natural gas.

The estimated frequency of blackout (probable events during the ship lifetime) is presented in Figure 6(e). In addition, the FOB values estimated in the various operating modes (when operating with a different number of generator sets) of the considerd optimal alternative solutions are presented and discussed in Appendix B. The predicted FOB values fluctuate between 7.0-10.4 blackouts per lifetime. As it can observed from Figure 6(e), the alternative No 3a FOB value is 5.8\% lower than the baseline one but higher than the FOB values of the other alternatives (No 1a, 2a and 4a), due to the fact that the No 3a plant operation with one generator set connected to the network is more frequent. These results are attributed to the operating profile and the characteristics of the specific power plants solutions (number of operating DG sets, type and size). As explained in Appendix B, the time percentage of the plant operation with one generator set is the dominant factor for the FOB calculation. The other alternatives (No 1a, 2a and 4a) FOB values are lower, as the plant operation with one generator set is more limited in these cases. It can be deduced from the results presented in Appendix B and in previous studies [4] that the probability of blackout is significantly reduced in case of limited plant operation with only one generator set. The present FOB values estimation for the presented alternatives is also consistent with the FOB estimation from available accident statistics [73]. The baseline power plant configuration was designed to comply with the imposed rules and regulations and therefore, it can be considedered to be safe. Since the presented alternatives results exhibit improved FOB values compared to the baseline, these designs can also be considered to be of enhanced safety. As it is explained in Appendx B, the fuel selection has only a slight impact on the estimated FOB values, whereas the number of the connected generator sets as well as their operating profile greately influences the system FOB.

The operating generator sets availability values are presented in Figure 6(f). As it can be inferred from this figure, the alternative solutions with 8 generator sets exhibit higher availability than the ones with 6 generator sets. The estimated unavailability values for the solutions No $1 a, 2 a, 4 a$ are ten times lower than the baseline. However, only slight percentage changes in the alternative solutions availability were calculated (as the availability values are higher than 0.99 ), which indicates that adequate plant redudancy is considered in all the investigated cases. 


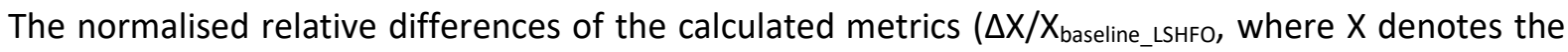
various presented metrics) from the respective values of the baseline power plant with LSHFO for the five investigated alternative solutions are presented in Figure 7. The baseline with LSHFO was selected herein as this configuration complies with the current emissions regulations (EEDI, NOx Tier II, and 2020 limits for SOx). It can be inferred from this figure that all the alternatives exhibit a comparable behaviour (with only slight differences) on the lifecycle NOx emissions and the generator sets availability, due to the compliance with the IMO Tier II limits and the considerable power plant redudancy selected for the investigated ship power plant, respectively. The alternative No 1a exhibits the best performance in the safety metric (FOB), however it performs the worst in the lifetime $\mathrm{CO}_{2}$ and SOx emissions, whereas it has a higher LCC than the baseline solution one. The alternative No 2a exhibits the lowest lifecycle NOx emissions as well as almost the lowest lifetime SOx emissions; it exhibits better $\mathrm{CO}_{2}$ emissions and $\mathrm{FOB}$ performance in comparison to the baseline respective metrics, whereas it is the worst alternative in terms of the LCC. The alternative No $4 a$ is the optimal alternative in terms of the $\mathrm{CO}_{2}$ and SOx emissions and the second best in terms of the LCC, whereas it exhibits a close to the best performance for the blackout frequency and the NOx emissions metrics. The alternative No 3a performs well in the majority of the objectives similarly to the alternative No 4a, however it exhibits a worse FOB. Based on the observed trade offs between the investigated alternatives, it can be inferred that the alternative No 4a (dual fuel generator sets operating with natural gas) manages to improve the environmental and economic performance of the power plant without compromising the system safety of the investigated cruise ship.

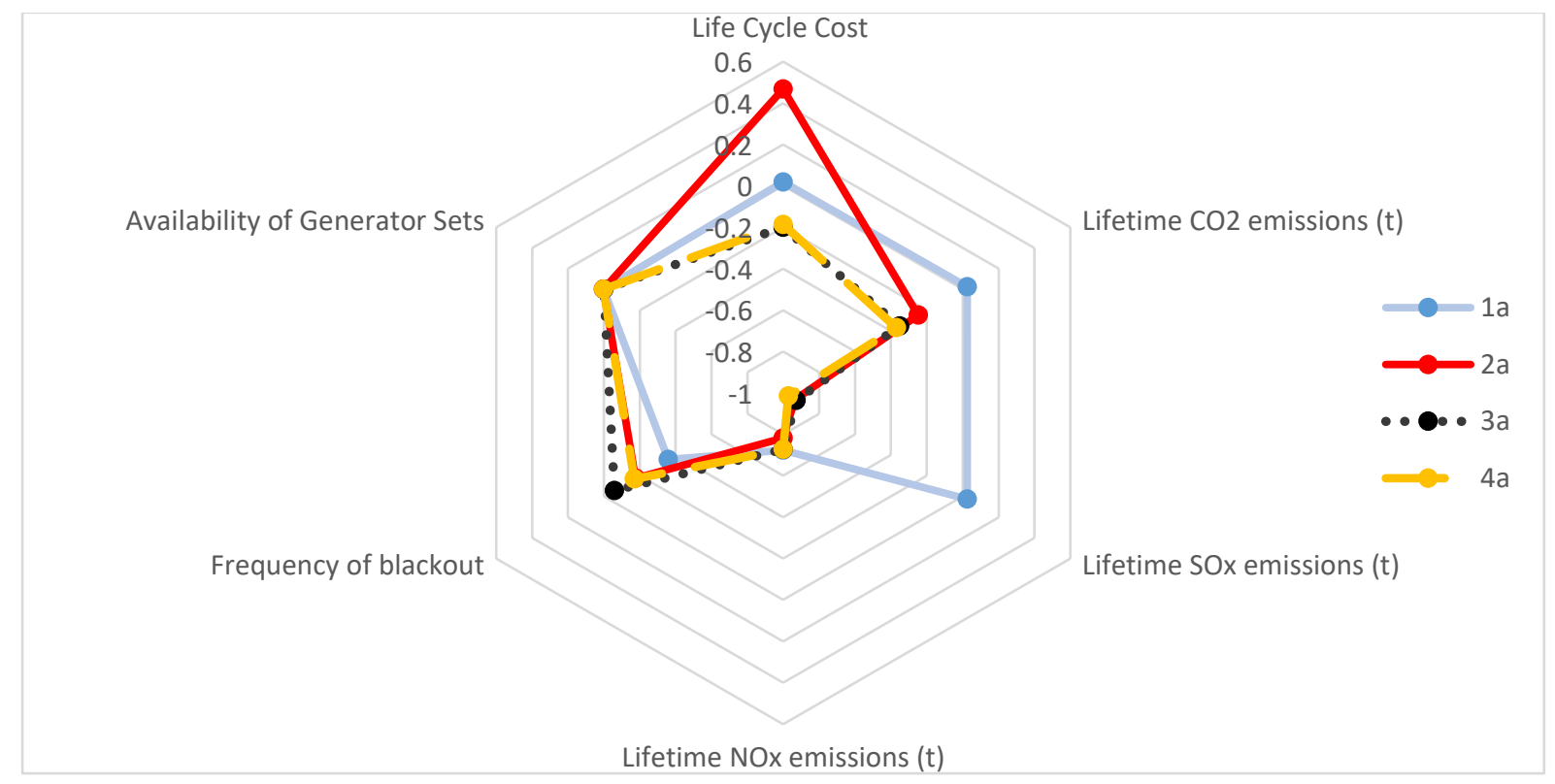

Figure 7 Normalised relative differences of the calculated metrics of the investigated cruise ship power plant alternative solutions derived for the first considered operating profile. 


\subsection{Higher propulsion power demand operational profile results}

For each selected fuel type (Table 2) and the second considered operating profile (with $10 \%$ higher propulsion power demand in comparison to the first operating profile shown in Figure 5(a)), the optimisation algorithm was employed to identify the optimal solutions characteristics (number of generator sets and their nominal power). The optimisation considered the two objectives (the lifecycle cost and the lifetime $\mathrm{CO}_{2}$ emissions) as well as the respective constraints for compliance with NOx and SOx emissions regulations. The derived optimal solutions with the lowest lifetime $\mathrm{CO}_{2}$ emissions for the selected fuels and fuels combinations are provided in Table 8. The complete solutions envelope as well as the Pareto fronts for this case are not presented for brevity purposes.

It is evident from the comparison of Table 7 and Table 8 results that although the number of the generator sets is similar with the ones of the optimal solutions derived by using the first operating profile, the selected generator sets nominal power is different. This is attributed to the fact that higher operating loads need to be satisfied, therefore generator sets with higher nominal power must be installed and operate in their most efficient load range. A considerable difference in the number and size of generator sets is observed when solutions No $3 \mathrm{a}$ and No $3 \mathrm{~b}$ are compared; although the total installed power is the same between the two solutions, uneven generator sets were selected in the case where the power requirements are higher.

The calculated economic, environmental and safety metrics, for the optimal alternatives, the baseline power plant as well as the baseline configuration operating with LSHFO are presented in Figure 8. For each solution, the percentage difference of the respective metric value from the baseline configuration value is also provided in this figure.

Table 8 Optimal configurations for each alternative power plant for second considered operating profile.

\begin{tabular}{|c|c|c|c|c|c|}
\hline Fuel type & $\begin{array}{l}\text { Type of } \\
\text { alternative } \\
\text { solutions } \\
\text { (Table 2) }\end{array}$ & $\begin{array}{l}\text { Operating } \\
\text { profile } \\
\text { (Figure 5) }\end{array}$ & $\begin{array}{l}1^{\text {st }} \text { Engine Type } \\
\text { Fuel } \\
\text { Emissions reduction } \\
\text { tecnologies } \\
\text { Number (-) } \\
\text { Unit Nominal Power }\end{array}$ & $\begin{array}{l}2^{\text {nd }} \text { Engine Type } \\
\text { Fuel } \\
\text { Emissions reduction } \\
\text { tecnologies } \\
\text { Number (-) } \\
\text { Unit Nominal Power }\end{array}$ & $\begin{array}{l}\text { Engine rooms } \\
\text { layout details }\end{array}$ \\
\hline $\begin{array}{l}\text { HFO or } \\
\text { LSHFO }\end{array}$ & 1 & $b$ & $\begin{array}{l}\text { D-G sets } \\
\text { HFO } \\
\text { SCR \& Scrubber } \\
4 \\
16 \mathrm{MW}\end{array}$ & $\begin{array}{l}\text { D-G sets } \\
\text { LSHFO } \\
\text { SCR } \\
4 \\
2 \mathrm{MW}\end{array}$ & $\begin{array}{l}\text { Engine room No 1: } \\
2 \text { units for each } \\
\text { engine type } \\
\text { Engine room No 2: } \\
2 \text { units for each } \\
\text { engine type }\end{array}$ \\
\hline $\begin{array}{l}\text { Methanol } \\
\& \text { MDO }\end{array}$ & 2 & $b$ & $\begin{array}{l}\text { DF-G sets } \\
\text { Methanol }\end{array}$ & $\begin{array}{l}\text { DF-G sets } \\
\text { Methanol }\end{array}$ & $\begin{array}{l}\text { Engine room No 1: } \\
2 \text { units for each } \\
\text { engine type }\end{array}$ \\
\hline
\end{tabular}




\begin{tabular}{|c|c|c|c|c|c|}
\hline & & & $\begin{array}{l}\text { Not included } \\
4 \\
6 \mathrm{MW}\end{array}$ & $\begin{array}{l}\text { Not included } \\
4 \\
12 \mathrm{MW}\end{array}$ & $\begin{array}{l}\text { Engine room No } 2 \text { : } \\
2 \text { units for each } \\
\text { engine type }\end{array}$ \\
\hline $\begin{array}{l}\text { HFO \& } \\
\text { Natural } \\
\text { Gas \& } \\
\text { MDO }\end{array}$ & 3 & b & $\begin{array}{l}\text { DF-G sets } \\
\text { NG (stored in LNG } \\
\text { form) } \\
\text { Not included } \\
4 \\
13 \mathrm{MW}\end{array}$ & $\begin{array}{l}\text { D-G sets } \\
\text { LSHFO } \\
\text { SCR } \\
4 \\
5 \mathrm{MW}\end{array}$ & $\begin{array}{l}\text { Engine room No 1: } \\
2 \text { units for each } \\
\text { engine type } \\
\text { Engine room No 2: } \\
2 \text { units for each } \\
\text { engine type }\end{array}$ \\
\hline $\begin{array}{l}\text { Natural } \\
\text { gas \& } \\
\text { MDO }\end{array}$ & 4 & b & $\begin{array}{l}\text { DF-G sets } \\
\text { NG (stored in LNG } \\
\text { form) } \\
\text { Not included } \\
4 \\
7 \mathrm{MW}\end{array}$ & $\begin{array}{l}\text { DF-G sets: } \\
\text { NG (stored in LNG } \\
\text { form) } \\
\text { Not included } \\
4 \\
11 \mathrm{MW}\end{array}$ & $\begin{array}{l}\text { Engine room No 1: } \\
2 \text { units for each } \\
\text { engine type } \\
\text { Engine room No 2: } \\
2 \text { units for each } \\
\text { engine type }\end{array}$ \\
\hline HFO & Baseline & b & $\begin{array}{l}\text { D-G sets } \\
\text { HFO } \\
\text { not included } \\
3 \\
12 \mathrm{MW}\end{array}$ & $\begin{array}{l}\text { D-G sets } \\
\text { HFO } \\
\text { not included } \\
3 \\
12 \mathrm{MW}\end{array}$ & $\begin{array}{l}\text { Engine room No 1: } \\
3 \text { units } \\
\text { Engine room No 2: } \\
3 \text { units }\end{array}$ \\
\hline
\end{tabular}

The LCC of the configurations in Figure 8 (a) is slightly higher than Figure 6 (a) due to the higher power demand that lead to higher fuel consumption and maintenance requirements. Similarly with Figure $6(a)$, the configuration that has the lowest LCC $(15.6 \%$ lower than the one of the baseline configuration) is the alternative that consists of a combination of dual fuel generator sets operating with natural gas and diesel generator sets (alternative No $3 \mathrm{~b}$ ). Another alternative with very low LCC (13.7\% lower LCC than the baseline one) is the alternative No $4 \mathrm{~b}$ that only consists of dual fuel generator sets.

The findings for the investigated alternatives performance in the LCC are similar with the findings reported in Section 4.1. The ranking of the identified optimal solutions in terms of their economic performance and gas emissions is the same as the previous case. A difference is observed in the alternative No $1 \mathrm{~b}$, which consists of 8 generator sets -4 DF-G and 4 D-G sets- (in comparison with the alternative No 1 a that consists of 6 generator sets) and has lower operating and capital cost (compared to the alternative No 1a that consists of diesel generator sets optimised for the first operating profile). This is due to the lower capital cost of this alternative (No 1b) as well as to the fact that a smaller scrubber is required for the solutions that operate with low sulphur fuel. In addition, the alternative No $1 \mathrm{~b}$ operating cost is lower despite the fact that low sulphur fuel has higher price than HFO, as the alternative No $1 \mathrm{~b}$ has lower maintenance and scrubbers consumables cost, due to the fact that the scrubber is needed for only the engines of the $1^{\text {st }}$ type. 

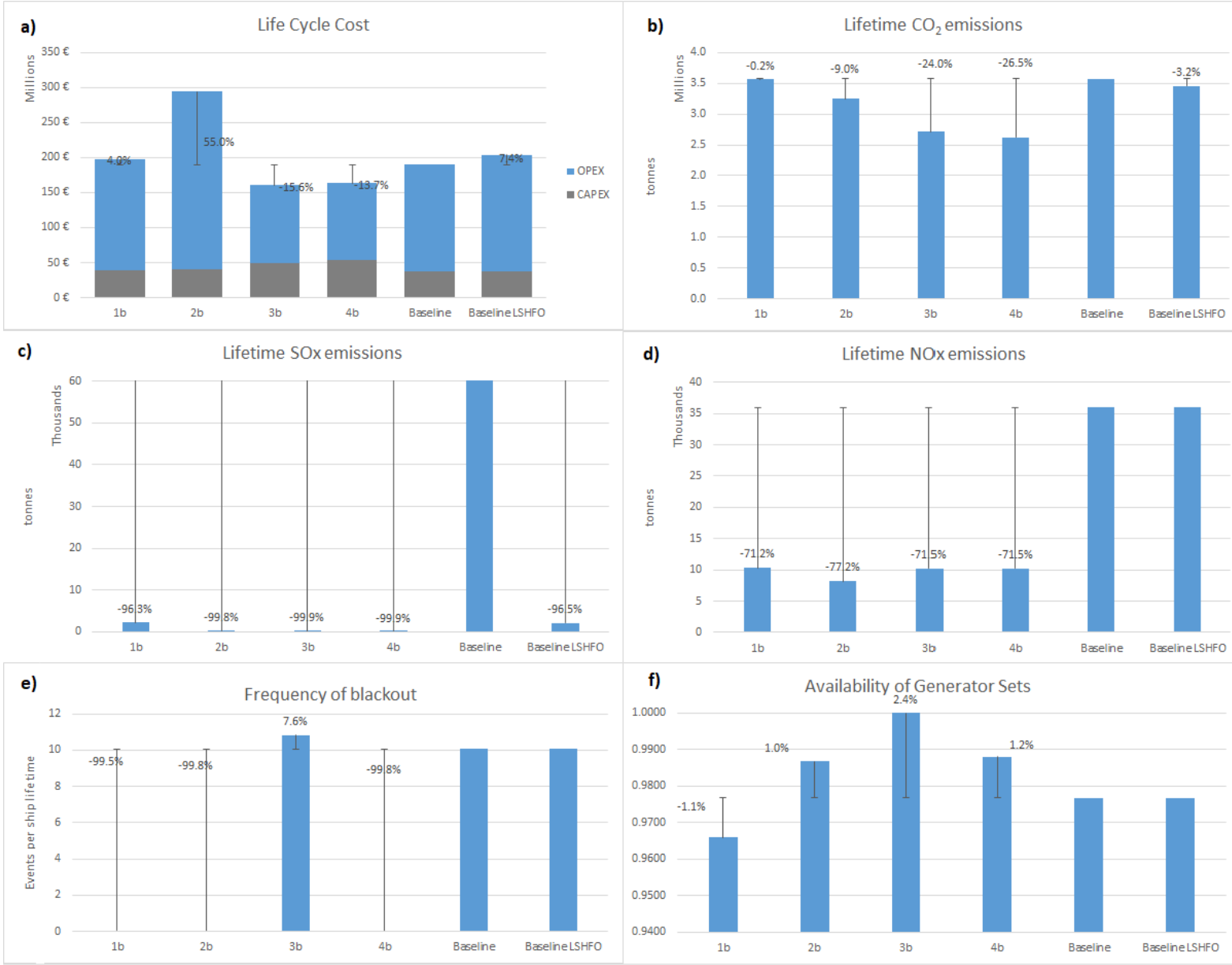

Figure 8 Lifetime economic, environmental and safety metrics of the investigated cruise ship power plant alternative solutions derived for the second considered operating profile.

The lifetime $\mathrm{CO}_{2}$ emissions of the alternatives derived for the second operating profile are displayed in Figure $8(b)$. Although the findings from the results presented in this figure are in alignment with the findings of the previous section, it is evident that the overall $\mathrm{CO}_{2}$ emissions are higher compared to the ones calculated for the first operating profile. As discussed above, this is due to the higher power demand and as a result, the higher consumed fuel amount. Similarly to the findings of the previous section, the alternatives that manage to improve the cruise ship carbon footprint are the following: No $4 \mathrm{~b}$-dual fuel generators sets operating with natural gas (26.5\% lower lifetime $\mathrm{CO}_{2}$ than the baseline power plant), No 3b-combination of dual fuel generator sets and diesel generator sets (24\% lower lifetime $\mathrm{CO}_{2}$ than the baseline power plant), and $\mathrm{No} 2 \mathrm{~b}$-dual fuel generator sets operating with methanol ( $9 \%$ lower lifetime $\mathrm{CO}_{2}$ than the baseline power plant). These alternatives can provide potential solutions contributing towards the IMO targets for $50 \%$ reduction of carbon emissions until 2050.

The results of the lifetime SOx emissions shown in Figure 8(c) also support the respective findings discussed in Section 4.2. The optimal power plants with dual fuel generator sets operating with natural 
gas or methanol comply with the future SOx limits regulations and can almost eliminate the SOX emissions.

The lifetime NOx emissions performance of the considered alternatives for the second operating profile are presented in Figure 8(d). The alternatives No 1b, 2b, 3b, and 4b manage to reduce by 71 $72 \%$ the NOx emissions in comparison to the baseline power plant. It is identified that the overall NOx emissions are higher compared to the original operating profile, due to the higher power requirements and the higher fuel consumption.

The frequency of blackout (FOB) and the generator sets availability is estimated for the identified optimal solutions as presented in Figure 8(e) and 8(f), respectively. The FOB is considerably decreased for the alternatives No $1 b, 2 b$ and $4 b(0.02$ to 0.05$)$, whereas the FOB value for the alternative No $3 b$ is 10.5 ( $7.6 \%$ increase from the baseline configuration FOB). This is attributed to the selected engines size (nominal power), which resulted in considerably reducing the power plant operating period with one generator set. As it can be deduced from the results presented in Appendix B, the FOB values for the case where only one generator set operates, are more than one order of magnitude higher than the respective values for the power plant operation with a number of generator sets. On the other hand, the configuration No $3 \mathrm{~b}$ exhibited the highest FOB value, as this power plant operates with one generator set for a considerable time period in the specific operating profile (due to the selected number and nominal power of the generator sets). The configuration No $1 \mathrm{~b}$ operates less frequently with one engine, as it includes engines with nominal size $2 \mathrm{MW}$, which are assumed to be connected first. Hence, for power above $2 \mathrm{MW}$, at least two engines operate. Similarly the configurations No $2 \mathrm{~b}$ and $4 \mathrm{~b}$ operate with at least two engines in power ranges above $6 \mathrm{MW}$ and $7 \mathrm{MW}$, respectively. On the contrary, the configuration No $3 \mathrm{~b}$, operates with one engine in power range from 0 to $13 \mathrm{MW}$, which increases the time percentage with one operating engine. This explains the high FOB value predicted for this configuration. Therefore, it is inferred that designs with a number of engines with relatively small nominal power can result in lower FOB values due to the smaller time percentage with one operating engine.

Similarly, to the findings of the previous section, the availability of the generator sets exhibits only a slight variation compared to the baseline due to the considerable redundancy of the units employed in the investigated power plants. It must be noted though that the availability for the second considered power plant operating profile (Figure $8(f)$ ) is reduced compared to the availability for the initial profile (Figure $6(f)$ ), due to the more frequent use of the generator sets.

Finally, the normalised relative differences of the calculated metrics from their respective baseline power plant with LSHFO values for the five investigated alternative solutions are presented in Figure 
9. The findings from the results of this figure are also aligned with the results of the previous section, although some differences are observed in the FOB of a number of alternatives as discussed above. The alternatives that consist of dual fuel generator sets operating in natural gas (alternative No 4b) as well as a combination of the dual fuel and diesel generator sets (alternative No $3 b$ ) exhibit the best performance in all the objectives (with the exception of FOB) despite the changes of the operating profile. However, as the FOB of the alternative No $4 \mathrm{~b}$ is considerably lower than the one of alternative No. $3 b$, variants of alternative No $3 b$ with reduced FOB need to be identified.

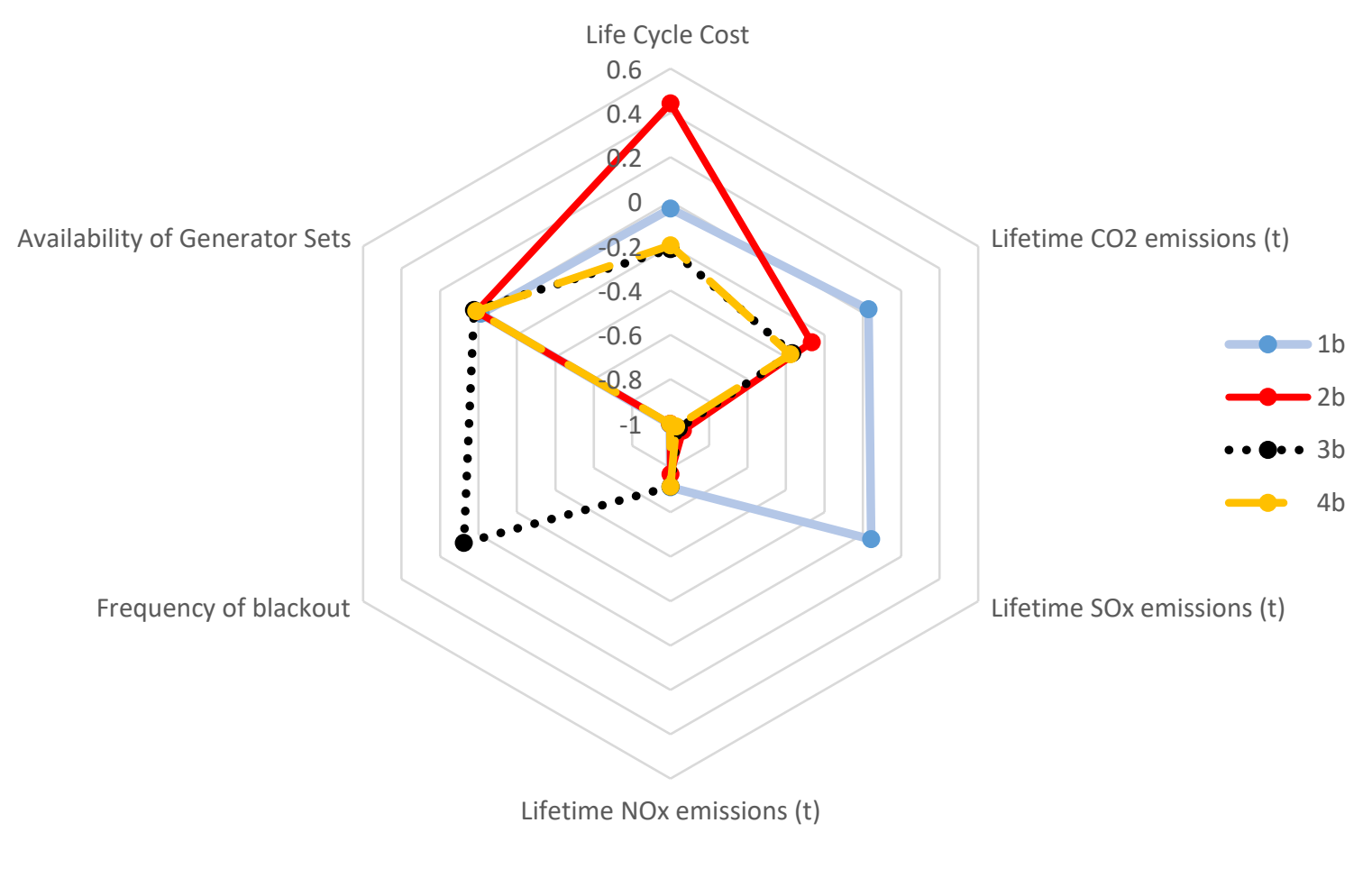

Figure 9 Normalised relative differences of the calculated metrics of the investigated cruise ship power plant alternative solutions derived for the second considered operating profile.

\section{Conclusions}

In the present study, the bi-objective optimisation of a cruise ship power plant was carried out. The NSGA-II algorithm was employed to identify the optimal solutions that minimise the lifecycle cost and the lifetime $\mathrm{CO}_{2}$ emissions for a number of selected fuels and fuels combinations. Two different operating profiles were used as input for the optimisation algorithm; the first corresponded to the actual conditions of a similar cruise ship, whereas the second considered a $10 \%$ higher propulsion power demand in comparison with the first. The existing and forthcoming IMO SOx and NOx regulations were used as constraints in the optimisation to ensure the compliance of the optimal solutions with the respective environmental regulatory framework. The identified optimal solutions were comparatively analysed to assess their performance on economic, environmental and safety 
metrics corresponding to the plant lifetime basis. The analysis resulted in solutions meeting the future cruise ship power plants challenging requirements that reduce the environmental footprint, provide compliance with the environmental regulations, ensure an acceptable economic performance and assure the appropriate safety level.

The main findings of this study are summarised as follows:

- The operating profile affected the generator sets nominal power selection without significantly affecting their number. A more uneven generator nominal power selection was derived for the case of the operating profile with the higher power demand as a higher number with higher nominal power is required to cover the increased power demand and the total installed power is fixed.

- The optimal cruise ship power plant solutions in terms of carbon emissions and cost-effectiveness do not necessary achieve the best performance in terms of safety metrics.

- The baseline configuration performance was the worst in all the employed environmental criteria. This configuration does not satisfy the future environmental regulations, and therefore appropriate solutions need to be proposed for the new cruise ship power plant designs.

- The identified power plant solutions running with methanol exhibited reduced emissions and improved safety metrics compared to the baseline due to less frequent operation with one generator set and increased redundancy in fuel supply, but they were associated with higher cost due to higher methanol price attributed to its presently lower market availability.

- The power plant solutions with dual fuel generator sets operating with natural gas managed to improve the environmental and economic performance of the cruise ship without compromising the ship safety. This solution was identified as one of the potential best alternatives for the future cruise ships power plants.

- The alternative combining dual fuel generator sets operating with natural gas and diesel generator sets running with LSHFO achieved a performance similar to the one of the dual fuel generator sets alternative with a slightly improved economic metric. This was attributed to the fact that the diesel generator sets running with LSHFO are utilised only for a limited operating time. This alternative can also be considered as a potential option in the cruise ships design.

- The frequency of blackout metric is highly affected by the operating time the power plant runs with one generator set. The operating time with one generator set depends on the nominal size of the generator sets. Therefore, configurations with small nominal power, which operate less frequently with one generator set, exhibit lower values of FOB and thus an enhanced safety level.

- The generators availability metric was very high due to the considerable redundancy that was considered for the investigated cruise ship power plant. However, when the operating profile with 
$10 \%$ higher propulsion power demand was used for optimisation, the generator sets availability in the baseline configuration and in the optimal solutions was reduced.

- The variation in availability values was small for the alternatives identified in each operating profile. In this respect, the inclusion of availability as an optimisation objective is not expected to facilitate the optimisation process in power plants of the same type. However, it is expected to be a meaningful objective for power plants of other ships types (ocean going vessels).

In summary, the results demonstrate that the presented approach can support decisions for identifying the cruise ships power plants optimal solutions that simultaneously reduce the lifecycle cost and emissions whilst enhancing the system safety. It is expected that such an approach will constitute a valuable tool for optimal design of the cruise ships and other ships power plants. In future work, the safety metrics could be incorporated in the optimisation, therefore offering a holistic optimisation of the cruise ship power plant.

\section{Acknowledgments}

The authors are grateful to Dr. Pierre C Sames from DNV GL AS and Kevin Douglas from Royal Caribbean for their valuable comments and support. The authors affiliated with the MSRC greatly acknowledge DNV GL AS and RCCL for their sponsorship for the establishment of the centre. The opinions expressed herein are those of the authors and should not be construed to reflect the views of DNV GL AS, RCCL or the acknowledged individuals and their associated organisations. 


\section{Nomenclature and Abbreviations Lists}

\section{Nomenclature list}

\begin{tabular}{|c|c|}
\hline$A$ & Availability [-] \\
\hline FOB & Frequency of Blackout for system [events/lifetime] \\
\hline$F O B_{p}$ & Frequency of Blackout in specific configuration [events/lifetime] \\
\hline$O P_{p}$ & percentage of time the system operates in a specific configuration [\%] \\
\hline$T_{i}$ & Inspection or maintenance interval $[\mathrm{h}]$ \\
\hline$U_{G}$ & Generator sets unavailability [-] \\
\hline$\frac{p_{i}^{O C}}{O C}$ & Probability of failure of operating component [-] \\
\hline$p_{i}^{S S}$ & Probability of failure of safety system [-] \\
\hline$p_{i}^{S S S}$ & Probability of specific system state [-] \\
\hline CAPEX & Capital Expenditure $[€]$ \\
\hline $\mathrm{C}_{\mathrm{c}}$ & Capital cost $[€ / \mathrm{kW}]$ \\
\hline $\mathrm{C}_{\mathrm{CO} 2}$ & $\mathrm{CO}_{2}$ conversion factor $\left[\mathrm{g} \mathrm{CO}_{2} / \mathrm{g}\right.$ fuel $]$ \\
\hline $\mathrm{C}_{\mathrm{m}}$ & Maintenance cost $[€ / \mathrm{kWh}]$ \\
\hline $\mathrm{d}_{\mathrm{r}}$ & Discount rate $[-]$ \\
\hline $\mathrm{d}_{\mathrm{f}}$ & Deterioration factor [-] \\
\hline EF & Emission Factor ( $\mathrm{t}$ pollutant/ $\mathrm{t}$ fuel for fuel based and $\mathrm{g} / \mathrm{kWh}$ for energy based) \\
\hline $\mathrm{fc}_{\mathrm{ft}, \mathrm{k}}$ & Fuel consumed [g] for different fuel types and operational phases [g] \\
\hline $\mathrm{h}_{\mathrm{k}}$ & Operating hours at the $\mathrm{k}^{\text {th }}$ operational phase $\mathrm{k}$ [hours] \\
\hline LHV & Lower Heating Value $[\mathrm{kJ} / \mathrm{kg}]$ \\
\hline $\mathrm{LTCO}_{2}$ & Life time carbon emissions $[\mathrm{g}]$ \\
\hline LTH & Ship lifetime operational time $[\mathrm{h}]$ \\
\hline LTNOx & Life time NOx emissions [g] \\
\hline LTSOx & Life time SOx emissions [g] \\
\hline $\mathrm{N}_{\mathrm{s}}$ & Number of systems of the same type $[-]$ \\
\hline OPEX & Operational expenditure $[€]$ \\
\hline $\mathrm{OPH}$ & Life time operating phases \\
\hline $\mathrm{P}_{\mathrm{k}, \mathrm{s}}$ & Instant power for operation phase $\mathrm{k}[\mathrm{kW}]$ \\
\hline $\mathrm{P}_{\mathrm{n}, \mathrm{s}}$ & Nominal power of the $\mathrm{s}^{\text {th }}$ system $\mathrm{s}[\mathrm{kW}]$ \\
\hline$P F D$ & The probability of failure on demand [-] \\
\hline$U$ & Unavailability [-] \\
\hline $\mathrm{X}$ & Presented metric in figures 7 and 9 \\
\hline $\mathrm{Y}$ & Ship lifetime [years] \\
\hline \multicolumn{2}{|l|}{ Subscripts } \\
\hline $\mathrm{ft}$ & Fuel type \\
\hline $\mathrm{k}$ & Operating phase, $\mathrm{k}=1-\mathrm{OPH}$ \\
\hline $\mathrm{s}$ & system \\
\hline \multicolumn{2}{|l|}{ Greek Symbols } \\
\hline$\beta_{i}$ & Weibull shape factor [-] \\
\hline$\lambda_{i}$ & Failure rate for component $\mathrm{i}\left[\mathrm{h}^{-1}\right]$ \\
\hline$\mu_{i}$ & Repair rate for component i $\left[\mathrm{h}^{-1}\right]$ \\
\hline
\end{tabular}


Abbreviations list

\begin{tabular}{|l|l|}
\hline BT & Bow Thrusters \\
\hline CASA & Combinatory Approach for Safety Assessment \\
\hline DE & Diesel engine \\
\hline DEP & Diesel-Electric Propulsion \\
\hline DFE & Dual-fuel engine \\
\hline DF-G & Dual-fuel Generators \\
\hline D-G & Diesel Generators \\
\hline ECA & Emission Control Areas \\
\hline ESI & Events Sequence Identification \\
\hline FOB & Frequency of Blackout \\
\hline FTA & Fault Tree Analysis \\
\hline HFO & Heavy Fuel Oil \\
\hline LNG & Liquified Natural Gas \\
\hline LSHFO & Low Sulphur Heavy Fuel Oil \\
\hline MDO & Marine Diesel Oil \\
\hline NG & Natural Gas \\
\hline NSGA-II & Non-sorting Genetic Algorithm II \\
\hline PM & Propulsion Motors \\
\hline PMS & Power Management System \\
\hline STPA & System-Theoretic Process Analysis \\
\hline UCA & Unsafe Control Actions \\
\hline
\end{tabular}




\section{Appendix A Derived Pareto front solutions with the first operational}

\section{profile}

The whole envelope of the solutions along with the Pareto fronts derived from the bi-objective optimisation for the first operating profile and the selected fuels and fuels combinations (denoted with 1a, 2a, 3a and 4a) are presented in Figure 10. The characteristics of the derived optimal configurations are provided in Table 9. For each fuel and fuel combination, the Pareto front solution with the lowest lifetime $\mathrm{CO}_{2}$ emissions is selected for further investigation of the safety metrics presented in Section 4.1.

As it can be observed from Figure 10, the employed optimisation algorithm identified only a few solutions for the cases 1 and 3, whereas only one optimal solution was identified for the cases 2 and 4 (methanol and natural gas, respectively). This is attributed to the fact that the solutions with the lowest lifetime fuel consumption simultaneously exhibit the lowest lifetime $\mathrm{CO}_{2}$ emissions and LCC. This is attributed to the following facts: (a) the emissions are estimated as a function of the fuel consumption, and (b) the fuel cost is the dominating part of the LCC. As it was presented in Section 2.2 , the LCC consists of the fuel cost, the capital cost, the maintenance cost and the consumables cost. The investigated power plants capital cost is estimated as function of the total installed nominal power, which is the same for all the configurations (according to the considered limitations), whereas the maintenance cost is calculated by employing the plant lifetime energy (in kWh) that depends on the operating profile. Hence, only one optimal solution is derived for the cases with one fuel (natural gas, methanol). On the other hand, in case 1 (diesel fuels), it is inferred that the combination of diesel generators operating with $\mathrm{HFO}, \mathrm{SCR}$ and scrubber provides the lowest lifetime $\mathrm{CO}_{2}$ emissions.

From the results presented in Table 9, it can be also inferred that the estimated safety metrics for the diesel fuel optimal solutions $\left(1 \mathrm{a}, 1^{*} \mathrm{a}\right.$ and $\left.1^{* *} \mathrm{a}\right)$ are identical. This is attributed to the similar engine number, sizing and operating profile. For the cases 2 and 4, only one optimal solution was identified; hence there is no need for deriving the trade-off between the different employed metrics. For the case with the dual fuel and diesel generator sets combination, the solution that has the greatest reduction on the carbon emissions is selected for further investigation of the safety metrics in Section 4.1. This solution exhibits a slightly higher FOB due to more frequent single generator operation compared to the other solutions of the Pareto front, but it also demonstrates significantly higher availability. It can be inferred from Table 9 that the investigated optimal solutions FOB values are within a specific range (7-10.4 events per ship lifetime). In addition, the calculated availability values are similar (0.9979-0.9999), whereas a slightly lower availability (0.9798) was calculated for the configuration $3^{*}$. It can be deduced from these remarks that the safety metrics do not vary 
considerably and therefore, the employed methodology (not including the safety metrics as objectives) can be employed as a first approach.

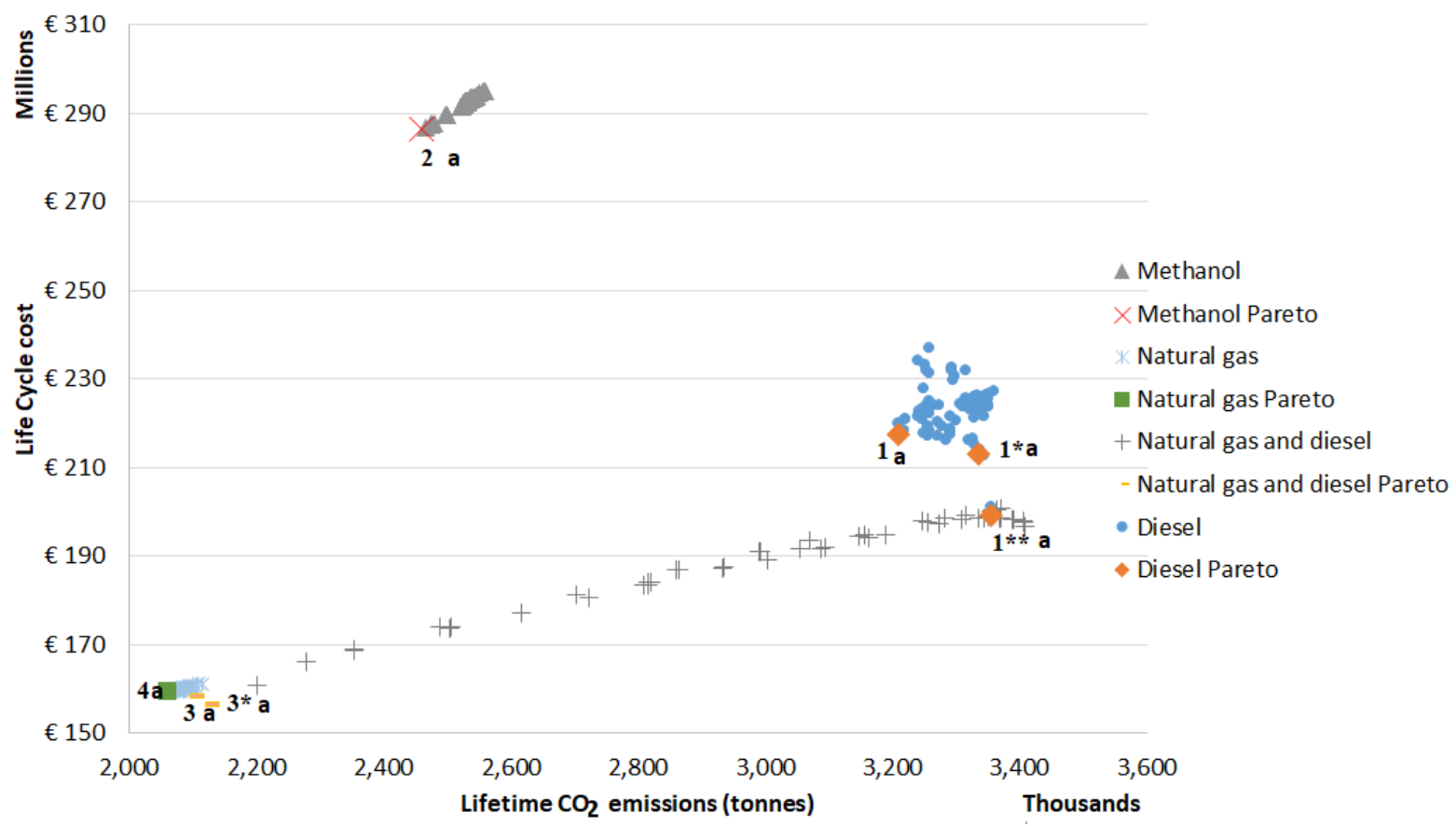

Figure 10 Derived Pareto fronts for the first operational profile and the following selected fuels and fuels combinations.

Table 9 Description of the derived alternative optimal solutions

\begin{tabular}{|c|c|c|c|c|c|}
\hline $\begin{array}{l}\text { Pareto } \\
\text { Front }\end{array}$ & $\begin{array}{l}\text { Type of } \\
\text { alternative } \\
\text { solutions }\end{array}$ & $\begin{array}{l}1^{\text {st }} \text { Engine Type } \\
\text { Fuel } \\
\text { Emissions reduction } \\
\text { tecnologies } \\
\text { Number (-) } \\
\text { Unit Nominal Power }\end{array}$ & $\begin{array}{l}2^{\text {nd }} \text { Engine Type } \\
\text { Fuel } \\
\text { Emissions reduction } \\
\text { tecnologies } \\
\text { Number (-) } \\
\text { Unit Nominal Power }\end{array}$ & $\begin{array}{l}\text { Frequency of } \\
\text { blackout } \\
\text { (events per } \\
\text { lifetime) }\end{array}$ & Availability (-) \\
\hline \multirow[t]{3}{*}{1} & $1 a$ & $\begin{array}{l}\text { D-G sets } \\
\text { HFO } \\
\text { SCR \& Scrubber } \\
4 \\
10 \mathrm{MW}\end{array}$ & $\begin{array}{l}\text { D-G sets } \\
\text { HFO } \\
\text { SCR \& Scrubber } \\
4 \\
8 \mathrm{MW}\end{array}$ & 7.06 & 0.9997 \\
\hline & $1 * a$ & $\begin{array}{l}\text { D-G sets } \\
\text { LHFO } \\
\text { SCR } \\
4 \\
10 \mathrm{MW}\end{array}$ & $\begin{array}{l}\text { D-G sets } \\
\text { HFO } \\
\text { SCR \& Scrubber } \\
4 \\
8 \mathrm{MW}\end{array}$ & 7.06 & 0.9997 \\
\hline & $1^{* * a}$ & $\begin{array}{l}\text { D-G sets } \\
\text { LHFO } \\
\text { SCR } \\
4 \\
10 \mathrm{MW}\end{array}$ & $\begin{array}{l}\text { D-G sets } \\
\text { LHFO } \\
\text { SCR } \\
4 \\
8 \mathrm{MW}\end{array}$ & 7.06 & 0.9997 \\
\hline
\end{tabular}




\begin{tabular}{|c|c|c|c|c|c|}
\hline 2 & $2 a$ & $\begin{array}{l}\text { DF-G sets } \\
\text { Methanol } \\
\text { Not included } \\
4 \\
11 \mathrm{MW}\end{array}$ & $\begin{array}{l}\text { DF-G sets } \\
\text { Methanol } \\
\text { Not included } \\
4 \\
7 \mathrm{MW}\end{array}$ & 9.05 & 0.9998 \\
\hline \multirow[t]{2}{*}{3} & $3 a$ & $\begin{array}{l}\text { DF-G sets } \\
\text { NG (stored in LNG form) } \\
\text { Not included } \\
4 \\
12 \mathrm{MW}\end{array}$ & $\begin{array}{l}\text { D-G sets } \\
\text { LSHFO } \\
\text { SCR } \\
2 \\
12 \mathrm{MW}\end{array}$ & 10.35 & 0.9979 \\
\hline & $3 * a$ & $\begin{array}{l}\text { DF-G sets } \\
\text { NG (stored in LNG form) } \\
\text { Not included } \\
4 \\
16 \mathrm{MW}\end{array}$ & $\begin{array}{l}\text { D-G sets } \\
\text { HFO } \\
\text { SCR \& Scrubber } \\
2 \\
4 \mathrm{MW}\end{array}$ & 7.84 & 0.9798 \\
\hline 4 & $4 a$ & $\begin{array}{l}\text { DF-G sets } \\
\text { NG (stored in LNG form) } \\
\text { Not included } \\
4 \\
11 \mathrm{MW}\end{array}$ & $\begin{array}{l}\text { DF-G sets: } \\
\text { NG (stored in LNG } \\
\text { form) } \\
\text { Not included } \\
4 \\
7 \mathrm{MW}\end{array}$ & 9.14 & 0.9999 \\
\hline
\end{tabular}




\section{Appendix B Calculated FOB for solutions with the first operational}

\section{profile}

For the optimal alternatives with the lowest lifetime $\mathrm{CO}_{2}$ emissions estimated using the first operational profile of the selected fuels and fuels combinations, the calculated FOB values with different numbers of operating generator sets are provided in Figure 11. As it can be deduced from this figure, the FOB values for the case where one generator set operates are several orders of magnitude higher than the respective FOB values when more generator sets operate. This is attributed to the additional redundancy in the generator sets number in other modes (with at least 2 operating generator set). In the cases where one generator set operates, the FOB for the various investigated optimal solutions exhibited similar values. This is attributed to the variation in failure rates for the physical components of the considered power plants, as different fuel systems are employed in each
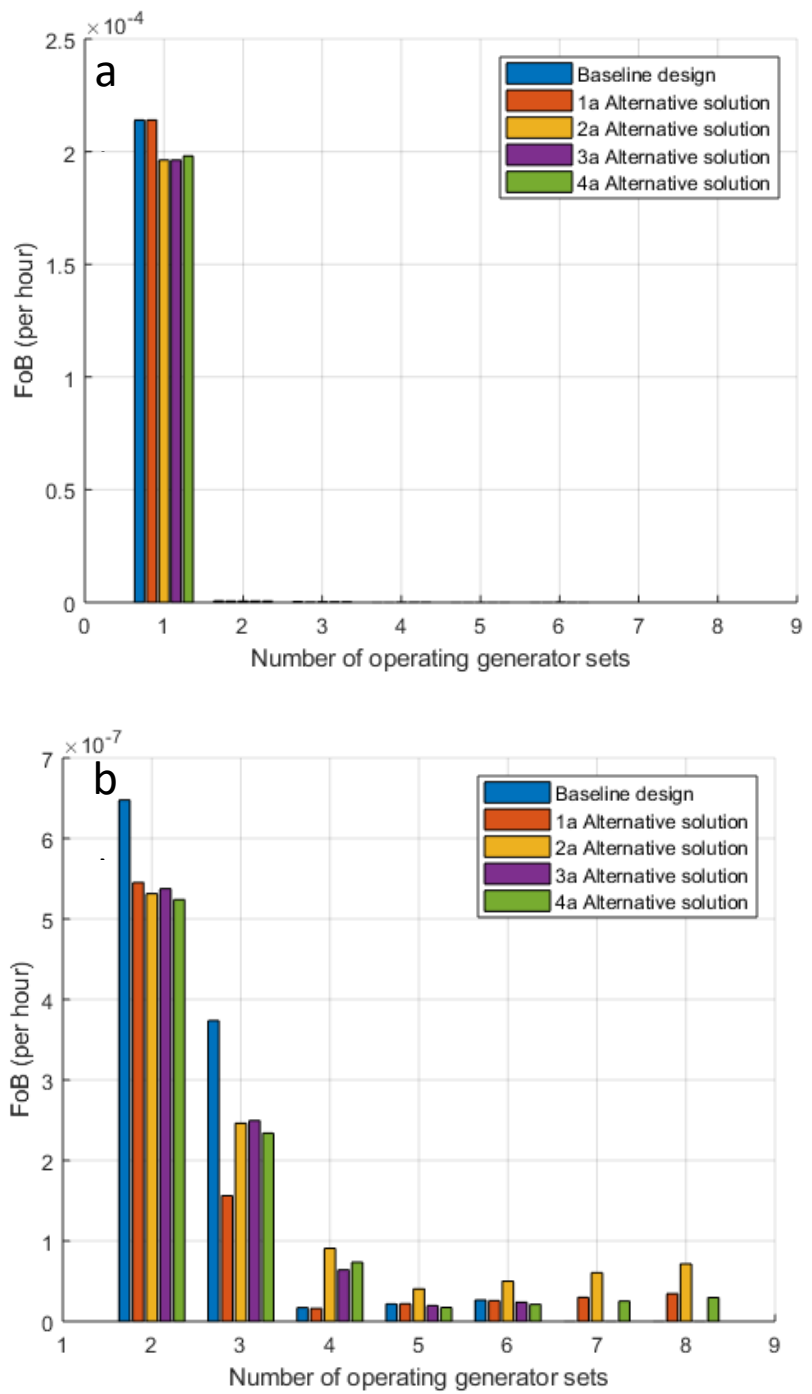

Figure 11 Calculated FOB for various numbers of operating generator sets (a) 1-8 generator sets; (b) 2-8 generator sets. 
optimal solution. Furthermore, the systems employing more than one fuel exhibit increased redundancy in fuel supply, which reduces the FOB due to failure in fuel supply system. When more than two generator sets are connected to the operating power plant, the variation in the predicted FOB values for the investigated optimal solutions are attributed to the considered generator sets loading conditions in each optimal solution, which in turn depends on the generator sets size and the considered cruise ship operational profile. The FOB values slightly increase when more than five generators operate. This is owing to the facts that more systems components can fail and the number of the non-operating (available to be connected when required) generator sets is too limited. In the latter case, tripping of one or more operating generator sets is more prone to lead to a black out event. 


\section{References}

[1] Cruise Lines International Association. 2017 cruise industry outlook. 2016.

[2] Sun X, Jiao Y, Tian P. Marketing research and revenue optimization for the cruise industry: A concise review. International Journal of Hospitality Management. 2011;30(3):746-55.

[3] Howitt OJA, Revol VGN, Smith IJ, Rodger CJ. Carbon emissions from international cruise ship passengers' travel to and from New Zealand. Energy Policy. 2010;38(5):2552-60.

[4] Bolbot V, Trivyza NL, Theotokatos G, Boulougouris E, Rentizelas A, Vassalos D. Cruise ship optimal power plants design identification and quantitative safety assessment. In: Theotokatos G, Corradu A, editors. 2nd International conference on modelling and optimisation of ship energy systems. Glasgow, Scotland: University of Strathclyde; 2019. p. 55-64.

[5] Bolbot V, Theotokatos G, Bujorianu LM, Boulougouris E, Vassalos D. Vulnerabilities and safety assurance methods in Cyber-Physical Systems: A comprehensive review. Reliability Engineering \& System Safety. 2019;182:179-93.

[6] Nilsen OV, Johansen CB, Knight M, Hoffman P, Skjong R. FSA for Cruise Ships - Task 4.1.1 - Hazid identification. Det Norske Veritas; 2005.

[7] MAIB. Report on the investigation of the catastrophic failure of a capacitor in the aft harmonic filter room on board RMS Queen Mary 2 while approaching Barcelona 23 September 2010. United Kingdom, Southampton2011.

[8] Ullah Z, Waldrop T, Chavez N. Helicopters sent to rescue 1,300 passengers from cruise ship off Norway. https://editioncnncom/2019/03/23/europe/norway-cruise-ship-evacuation/indexhtml2019.

[9] DNVGL. Guidance for safe return to port projects. DNVGL-CG-00042016.

[10] Balcombe P, Brierley J, Lewis C, Skatvedt L, Speirs J, Hawkes A, et al. How to decarbonise international shipping: Options for fuels, technologies and policies. Energy Conversion and Management. 2019;182:72-88.

[11] Panasiuk I, Turkina L. The evaluation of investments efficiency of SOx scrubber installation. Transportation Research Part D: Transport and Environment. 2015;40:87-96.

[12] Tzannatos E, Papadimitriou S, Koliousis I. A Techno-Economic Analysis of Oil vs. Natural Gas Operation for Greek Island Ferries. International Journal of Sustainable Transportation. 2015;9(4):272-81.

[13] World Maritime News. MethaShip: Renewable Methanol is 'Fuel with a Future'. https://worldmaritimenewscom/archives/263017/methaship-renewable-methanol-is-fuel-with-a-future/2018.

[14] Grahn M, Taljegård M, Bengtsson S, Andersson K, Johnson H. Cost-effective choices of marine fuels under stringent carbon dioxide targets. Conference Cost-effective choices of marine fuels under stringent carbon dioxide targets.

[15] Lasselle S, Hustad H, Vedeler J, Abusdal H. Methanol as marine fuel: Environmental benefits, technology readiness and economic feasibility. DNV GL; 2016.

[16] Trivyza NL, Rentizelas A, Theotokatos G. Impact of carbon pricing on the cruise ship energy systems optimal configuration. Energy. 2019;175:952-66.

[17] Jianyun Z, Li C, Lijuan X, Bin W. Bi-objective optimal design of plug-in hybrid electric propulsion system for ships. Energy. 2019;177:247-61.

[18] Dimopoulos GG, Kougioufas AV, Frangopoulos CA. Synthesis, design and operation optimization of a marine energy system. Energy. 2008;33(2):180-8.

[19] Baldi F, Maréchal F, Tammi K. Process integration as a tool for the improvement of cruise ships energy efficiency. Conference Process integration as a tool for the improvement of cruise ships energy efficiency. p. 4-5. [20] Wik C. Tier III technology development and its influence on ship installation and operation. CIMAC Congress. Shanghai, China2013.

[21] Bassam AM, Phillips AB, Turnock SR, Wilson PA. An improved energy management strategy for a hybrid fuel cell/battery passenger vessel. International Journal of Hydrogen Energy. 2016;41(47):22453-64.

[22] Armellini A, Daniotti S, Pinamonti P, Reini M. Evaluation of gas turbines as alternative energy production systems for a large cruise ship to meet new maritime regulations. Applied Energy. 2018;211:306-17.

[23] Baldi F, Ahlgren F, Melino F, Gabrielii C, Andersson K. Optimal load allocation of complex ship power plants. Energy Conversion and Management. 2016;124:344-56.

[24] Ancona MA, Baldi F, Bianchi M, Branchini L, Melino F, Peretto A, et al. Efficiency improvement on a cruise ship: Load allocation optimization. Energy Conversion and Management. 2018;164:42-58.

[25] Jeong B, Oguz E, Wang H, Zhou P. Multi-criteria decision-making for marine propulsion: Hybrid, diesel electric and diesel mechanical systems from cost-environment-risk perspectives. Applied Energy. 2018;230:1065-81. 
[26] Yan $Y$, Zhang $H$, Long Y, Wang Y, Liang Y, Song X, et al. Multi-objective design optimization of combined cooling, heating and power system for cruise ship application. Journal of Cleaner Production. 2019;233:264-79.

[27] Solem S, Fagerholt K, Erikstad SO, Patricksson $\varnothing$. Optimization of diesel electric machinery system configuration in conceptual ship design. Journal of Marine Science and Technology. 2015;20(3):406-16.

[28] Ahlgren F, Mondejar ME, Genrup M, Thern M. Waste Heat Recovery in a Cruise Vessel in the Baltic Sea by Using an Organic Rankine Cycle: A Case Study. Journal of Engineering for Gas Turbines and Power. 2015;138(1):011702--10.

[29] Baldi F, Ahlgren F, Nguyen T-V, Thern M, Andersson K. Energy and Exergy Analysis of a Cruise Ship. Energies. 2018;11(10).

[30] Chang D, Rhee T, Nam K, Chang K, Lee D, Jeong S. A study on availability and safety of new propulsion systems for LNG carriers. Reliability Engineering \& System Safety. 2008;93(12):1877-85.

[31] Vedachalam N, Ramadass GA. Reliability assessment of multi-megawatt capacity offshore dynamic positioning systems. Applied Ocean Research. 2017;63:251-61.

[32] Dubey A, Santoso S, Arapostathis A. Reliability analysis of three-dimensional shipboard electrical power distribution systems. In: Dougal R, editor. 2015 IEEE Electric Ship Technologies Symposium (ESTS). Washington DC, USA2015. p. 93-8.

[33] Santoso S, Arapostathis A, Abdelwahed S, Amgai R, Cartes D, Soman R, et al. Improving reliability of MVDC ship power system. Office of Naval Research; 2015.

[34] Sfakianakis K, Vassalos D. Design for safety and energy efficiency of the electrical onboard energy systems. In: Dougal R, editor. 2015 IEEE Electric Ship Technologies Symposium. Washington DC, USA2015. p. 150-5.

[35] Bolbot V, Theotokatos G, Bujorianu LM, Boulougouris E, Vassalos D, Psarros G, et al. A novel method for safety assessment of Cyber-Physical Systems - Application to cruise ship Diesel-Electric Propulsion plant blackout prediction. Internal MSRC report - available upon request2019.

[36] Deb K, Pratap A, Agarwal S, Meyarivan T. A fast and elitist multiobjective genetic algorithm: NSGA-II. IEEE Transactions on Evolutionary Computation. 2002;6(2):182-97.

[37] Cichowicz J, Theotokatos G, Vassalos D. Dynamic energy modelling for ship life-cycle performance assessment. Ocean Engineering. 2015;110:49-61.

[38] Turbo MD. MAN L35/44DF Project Guide - Marine Four-Stroke Dual Fuel Engines Compliant with IMO Tier II. 2017.

[39] Trivyza NL, Rentizelas A, Theotokatos G. A novel multi-objective decision support method for ship energy systems synthesis to enhance sustainability. Energy Conversion and Management. 2018;168:128-49.

[40] Bolbot V, Theotokatos G, Vassalos D. Using system-theoretic process analysis and event tree analysis for creation of a fault tree of blackout in the Diesel-Electric Propulsion system of a cruise ship. International Marine Design Conference XIII. Helsinki, Finland: CRC Press; 2018. p. 691-9.

[41] Leveson NG. Engineering a safer world: Systems thinking applied to safety. London, England: The MIT press, 2011.

[42] Watson H. Launch control safety study. Bell labs. 1961.

[43] Schüller J, Brinkman J, Van Gestel PJ, Van Otterloo R. Methods for Determining and Processing Probabilities: Red Book: Committee for the Prevention of Disasters, 1997.

[44] Verma AK, Srividya A, Karanki DR. Reliability and safety engineering: Springer, 2010.

[45] Bolbot V, Theotokatos G, Boulougouris E, Vassalos D. Comparison of diesel-electric with hybrid-electric propulsion system safety using System-Theoretic Process Analysis. Propulsion and Power Alternatives. London, United Kingdom: Royal Institute of Naval Architects; 2019. p. 55-61.

[46] Bunker S. World bunker prices. 2018.

[47] Methanex. Methanol prices. 2018.

[48] Livanos GA, Theotokatos G, Pagonis D-N. Techno-economic investigation of alternative propulsion plants for Ferries and RoRo ships. Energy Conversion and Management. 2014;79:640-51.

[49] Pelet X, Favrat D, Leyland G. Multiobjective optimisation of integrated energy systems for remote communities considering economics and $\mathrm{CO} 2$ emissions. International Journal of Thermal Sciences. 2005;44(12):1180-9.

[50] Lövblad G, Fridell E. Experiences from use of some techniques to reduce emissions from ships. 2006.

[51] Tremuli P. Developments and Perspectives of Marine Engines. Clean Combustion and Greenhouse Gases, Brussels. 2008;6.

[52] OREDA Participants. Offshore reliability data handbook. Norway, Hovik2015.

[53] Aldemir T, Stovsky M, Kirschenbaum J, Mandelli D, Bucci P, Mangan L, et al. Dynamic reliability modeling of digital instrumentation and control systems for nuclear reactor probabilistic risk assessments. NUREG0CR-6942, US Nuclear Regulatory Commission. 2007. 
[54] Chai M, Reddy DB, Sobrayen L, Panda KS, Die W, Xiaoqing C. Improvement in efficiency and reliability for diesel- electric propulsion based marine vessels using genetic algorithm. Conference Improvement in efficiency and reliability for diesel- electric propulsion based marine vessels using genetic algorithm. p. 180-4.

[55] Aquilino JW. Report of transformer reliability survey-industrial plants and commercial buildings. IEEE transactions on industry applications. 1983(5):858-66.

[56] ABB. Reliability calculation in accordance with RDF93 model from CNET. 2005.

[57] Allal AA, Mansouri K, Youssfi M, Qbadu M. Toward a reliable sea water central cooling system for a safe operation of autonomous ship. International Journal of Industrial Electronics and Electrical Engineering. 2017;5(12):10.

[58] Anantharaman M, Khan F, Garaniya V, Lewarn B. Reliability of Fuel Oil System Components Versus Main Propulsion Engine: An Impact Assessment Study. Safety of Marine Transport: Marine Navigation and Safety of Sea Transportation. 2015:175.

[59] Berghmans F, Eve S, Held M. An introduction to reliability of optical components and fiber optic sensors. Optical Waveguide Sensing and Imaging: Springer; 2008. p. 73-100.

[60] Chybowski L, Idziaszczyk D, Wiśnicki B. A comparative components importance analysis of a complex technical system with the use of different importance measures. Systemy Wspomagania w Inżynierii Produkcji. 2014(1

(7)):23--33.

[61] IMO. Formal Safety Assessment - Cruise ships. 2008.

[62] Menis R, da Rin A, Vicenzutti A, Sulligoi G. Dependable design of all electric ships integrated power system: Guidelines for system decomposition and analysis. Electrical Systems for Aircraft, Railway and Ship Propulsion (ESARS). Bologna, Italy: IEEE; 2012. p. 1-6.

[63] SINTEF. Reliability data for safety instrumented systems PDS Data Handbook2006.

[64] Siemens. Arcing faults in medium-voltage and low-voltage switchgear. 2013.

[65] Van Ta T, Thien DM, Cang VT. Marine Propulsion System Reliability Assesment by Fault Tree Analysis.

[66] Jin X, Wang C, Chen C, Cheng T, Amancio A. Reliability analyses and calculations for distribution transformers. Conference Reliability analyses and calculations for distribution transformers, vol. 2. IEEE, p. 901-6.

[67] Bloch HP, Geitner FK. Machinery failure analysis and troubleshooting: practical machinery management for process plants: Butterworth-Heinemann, 2012.

[68] Mihanović L, Komar I, Gržan M. Methodology analysis using exploitation reliability with the use of the RTOP main diesel engine. NAŠE MORE: znanstveno-stručni časopis za more i pomorstvo. 2016;63(2):48-55.

[69] Ossai Cl, Boswell B, Davies IJ. Estimation of internal pit depth growth and reliability of aged oil and gas pipelines-A Monte Carlo simulation approach. Corrosion. 2015;71(8):977-91.

[70] Dolas DR, Deshmukh S. Reliability Ananlysis of Cooling System of Diesel Engine. Universal Journal of Mechanical Engineering. 2015;3(2):57-62.

[71] Bukša A, Šegulja I, Tomas V. Ship Machinery Maintenance Concept Adjustment and Design. Strojarstvo: časopis za teoriju i praksu u strojarstvu. 2009;51(3):227-38.

[72] Toolkit RA. Failure rate estimates for mechanical components. 2018.

[73] Friis-Hansen P, Ravn E, Engberg P. Basic modelling principles for prediction of collision and grounding frequencies. IWRAP Mark II Working Document. 2008:1-59. 